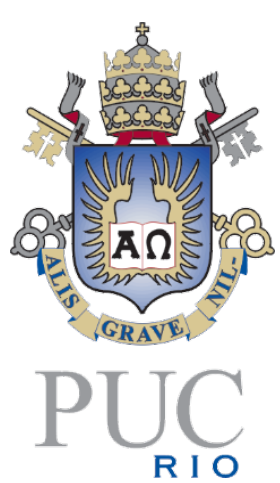

Pontifícia Universidade Católica do Rio de Janeiro

\title{
Um Estudo Sobre a Integração Cultural e Estrutural da BHGE Gabriel Cecilio Ferreira
}

Trabalho de Conclusão de Curso

Centro de Ciências Sociais - CSS

Departamento de Administração

Graduação em Administração de Empresas 


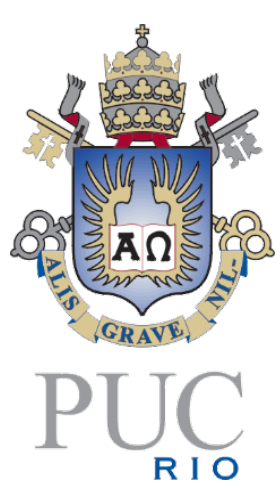

Gabriel Cecilio Ferreira

\section{Um Estudo Sobre a Integração Cultural e Estrutural da BHGE}

\section{Trabalho de Conclusão de Curso}

Trabalho de Conclusão de Curso, apresentado ao programa de graduação em Administração da PUC-Rio como requisito parcial para a obtenção do título de graduação em Administração.

Orientadora: Mila Desouzart de Aquino Viana 
"Encare a realidade como ela é, não como ela foi ou como você quer que ela seja" Jack Welch 


\section{Agradecimentos}

Esse trabalho foi feito com muita dedicação para concluir um curso pelo qual me apaixonei nos 4 anos e meio que cursei. Foram anos de muito aprendizado, trabalhos em grupo, resumos, estudo e amizades.

Gostaria de agradecer aos incríveis professores que tive e que me guiaram nessa jornada. Dentre os muitos, um agradecimento especial à: Mila Viana, minha orientadora, Nelson Dabul, Andrea Cherman, Renata Kurtz, Graziela Fortunato e Ana Maria, que além de professores incríveis possibilitaram a realização de um sonho que era estudar fora.

Aos meus queridos amigos, Enzo, Fernandes e Daniel, honestamente não consigo lembrar da minha vida antes de conhece-los e não quero imaginá-la sem vocês. Vocês estiveram comigo nos melhores e nos piores momentos, da minha vida e são os meus melhores amigos e, não há nada que não faria por vocês. Hoje, mesmo com todos formados e com cada um seguindo o seu caminho, seja no óleo e gás, mercado financeiro ou na academia, no Brasil ou nos EUA, tenho certeza que sempre encontraremos formas de estar juntos.

Ao Acquarone, um dos meus melhores amigos desde a escola e fechamento certo pra qualquer coisa. Não há nada, tirando ir te buscar de carro na casa da Pamela (sim, você tem dois pés e pode andar por cinco minutos), que não faria por você, pode contar sempre comigo.

À Pamela, que já deixou de ser namorada de um amigo pra se tornar uma das minhas melhores amigas há muito tempo. De companheira da Forma até dona da Velocity, fechamento certo no Gurume, mesmo você monopolizando as comemorações no nosso mês de aniversário já se tornou uma das pessoas mais especiais na minha vida.

À Bia, do ônibus, do Santo Inácio e do Piraquê pra vida. Uma das pessoas mais incríveis, inteligentes e dedicadas que eu conheço, parceira de bike (to devendo, mas a formatura ta chegando e a esperança é a última que morre), rata de praia, amiga para qualquer hora, amante do carnaval e sem dúvida nenhuma, minha advogada. O mundo é muito pequeno pra você e um dia tenho certeza que ouviremos muito falar da Gomes \& Associados, conta sempre comigo.

À Joana, não há ninguém com mais Graça do que você. Não sei nem há quanto tempo está na minha vida, mas sei que não é nem metade do que será. Parceira de night, de Lolla, de chef por um dia e de todo resto, você é sensacional, uma das minhas melhores amigas e vou estar sempre aqui por você (a não ser que você encontre um Fusca rosa pegando fogo no sinal, se esse momento chegar estarei bem longe).

Ao Mirandinha, de longe a melhor pessoa. Um cara incrível, parceiro de Desert Trip, feijoada e churrasco, não há ninguém que vai mais longe que você, volta logo da França que você não imagina a falta que faz. 
Ao Hugo, meu amigo desde a escola e fechamento certo. Honestamente não sei o que teria sido o intercâmbio sem você junto, só a gente sabe o quão certa foi a escolha de passar um ano fora. Fica tranquilo que mesmo tendo voltado ainda vão rolar muitas viagens absurdas que com certeza a gente não vai planejar.

Ao , Acquarone, Hugo, Pamela, Armando, uma instituição do Carnaval Carioca. A pessoa que sustenta sozinho a indústria de celulares do país e que, graças a tudo que existe de bom, tem o melhor senso de direção para encontrar o caminho de casa.

Ao Dudu, infelizmente vascaíno, mas uma pessoa incrível e um dos meus melhores amigos.

Ao Paulinho, Luiz e o Henrique, que entraram na turma no $9^{\circ}$ ano e jamais saíram. Vocês são incríveis e embora não nos encontremos com a mesma frequência serão sempre alguns dos meus melhores amigos.

Ao Moura, o rei do Pilotis, Arthur e Caetano, grandes amigos de JB Investimentos, de resenhas passadas e futuras, espero que todos voltem ao Rio para mais noites musicais.

Ao Moura, Miranda, Caetano, Arthur, Dudu, Henrique, Bernardo, Léo, Davi, Guilherme, Fábio, Matheus e Allan , Joana e Maria Beatriz, que dentre outros estiveram comigo durante toda essa jornadae fizeram dos períodos iniciais os melhores que tive..A todos os outros amigos que não pude agradecer individualmente, mas que tiveram um impacto na minha, muito obrigado.

A minha família, meu pai José Mauricio, minha mãe Glória e meu irmão Matheus, que sempre me apoiaram e me deram as ferramentas e o suporte para não só concluir esse curso, mas para me moldar como a pessoa que sou hoje e vou me tornar no futuro.

Ao Chico, meu companheiro de quatro patas que esteve do meu lado durante últimos quase 13 anos, venceu um câncer e ainda me acompanhará em muitas aventuras.

A minha incrível equipe na BHGE, que desde o início me desafiou e me desenvolveu, sempre tentando me ajudar. Um obrigado especial à Cleber Depizzol, Domenico Derosa, Rodrigo Menezes, Victor Jansen, Jeffrey Hoke, Marcelo Brahim, Jeff Hoke, e David Santana e Fabio Bianchi.

A todos aqui mencionados, vocês tiveram um enorme impacto na minha vida e só Ihes tenho a agradecer, contem comigo para tudo. 


\section{Resumo}

Cecilio Ferreira, Gabriel. Um estudo sobre a integração cultural estrutural da BHGE. Rio de Janeiro, 2019. Número de páginas 420. Trabalho de Conclusão de Curso - Departamento de Administração. Pontifícia Universidade Católica do Rio de Janeiro.

Esse trabalho buscou analisar a integração cultural e estrutural da Baker Hughes, a GE Company. Esse grande player do setor de serviços e equipamentos de óleo e gás foi formado em 2016 com a aquisição da Baker Hughes por parte da General Electric e fusão com a sua subsidiária GE Oil \& Gas. O trabalho buscou através de entrevistas com membros da organização e comparação com os conhecimentos acadêmicos entender e avaliar o processo de integração escolhido, 3 anos após a fusão.

\section{Palavras-chave}

General Electric; Fusão; M\&A; Aquisição; Baker Hughes; Óleo e Gás 


\section{Abstract}

Cecilio Ferreira, Gabriel.A study about BHGE's cultural and structural integration. Rio de Janeiro, 2019. Page number 420. Trabalho de Conclusão de Curso - Departamento de Administração. Pontifícia Universidade Católica do Rio de Janeiro.

This article sought to analyze the cultural and structural integration of Baker Hughes, a GE Company. This huge player of the oil \& gas services and equipment sector was formed in 2016 with the acquisition of Baker Hughes by General Electric and sub sequential merger with its GE Oil \& Gas subsidiary. The article sought, through interviews with members of the organization and comparison with the academic theory, to understand and analyze the chosen integration process 3 years after the merger.

Key-words

General Electric; Merger; M\&A; Acquisition; Baker Hughes; Oil \& Gas 


\section{Sumário}

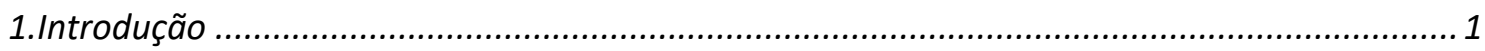

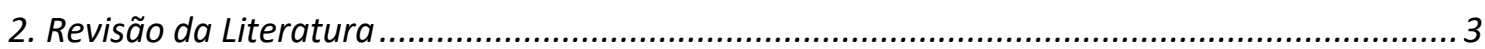

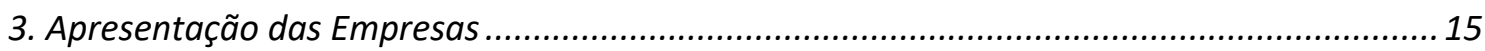

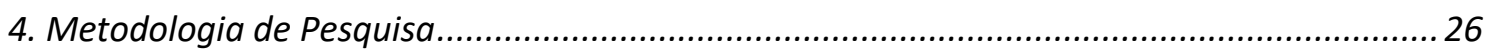

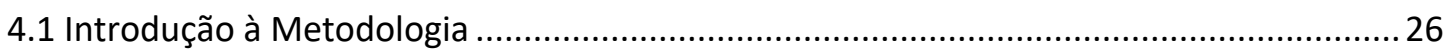

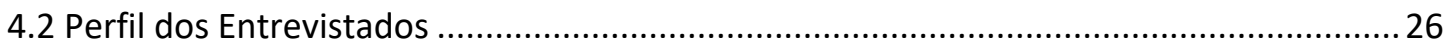

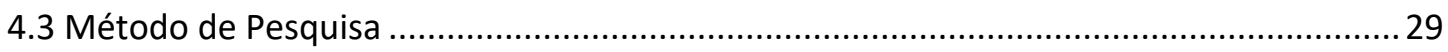

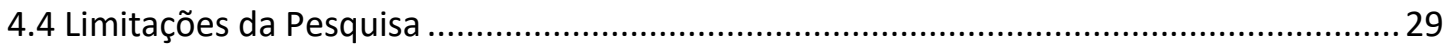

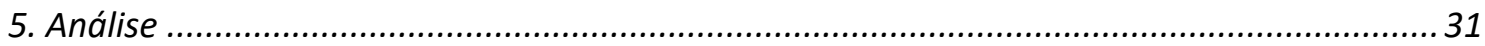

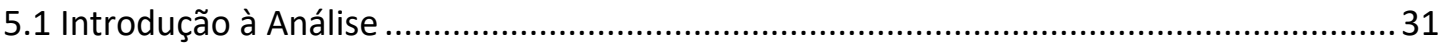

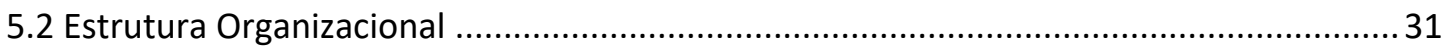

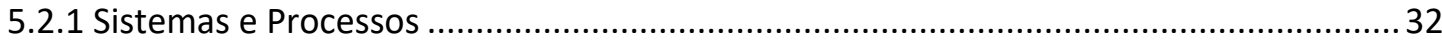

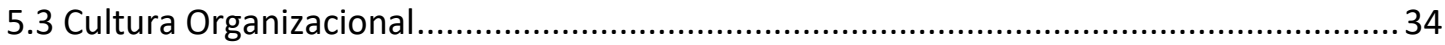

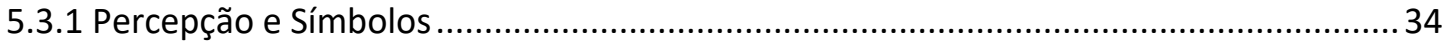

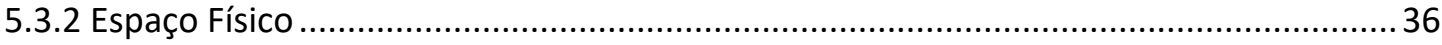

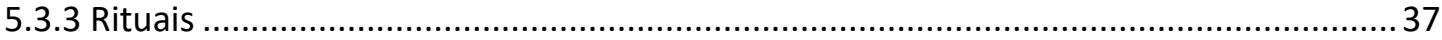

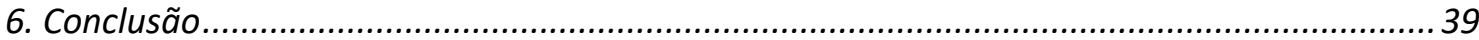

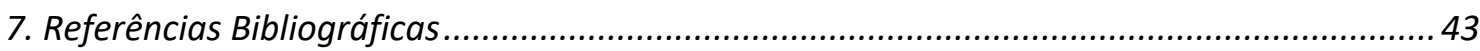




\section{Introdução}

No dia 3 de julho de 2017 a General Electric (GE) anunciou oficialmente a aquisição da Baker Hughes e a fusão da mesma com a já existente GE Oil \& Gas (BAKER HUGHES, A GE COMPANY, 2017). O resultado dessa união passou a ser conhecido como Baker Hughes, a GE Company (BHGE), uma empresa que tem $62,5 \%$ do seu capital controlado pela GE e 37,5\% trocado publicamente na bolsa de Nova lorque (HAMPTON e SCHEYDER, 2017).

A união das duas empresas centenárias criou a primeira, e até hoje, única empresa fullstream do mundo. O objetivo da GE com isso era, atuar em toda a cadeia de valor do setor e agregando o uso de novas tecnologias, gerar uma vantagem competitiva para a BHGE, que teria economias de escala e conseguiria vender projetos de soluções completas e integradas para seus clientes.

Figura 1: Modelo de negócio fullstream

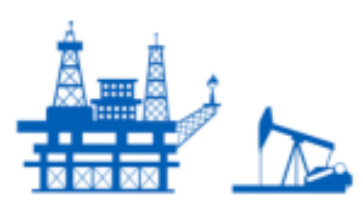

UPSTREAM

Evaluation, Drilling, Completion \& Production

\section{FULLSTREAM}

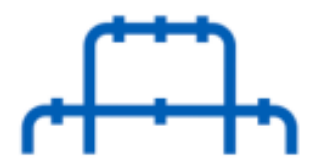

MIDSTREAM

LNG, Pipeline \& Storage

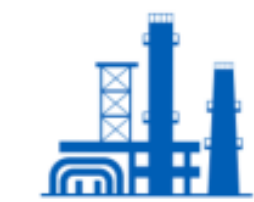

DOWNSTREAM

Refinery \& Petrochemical Solutions

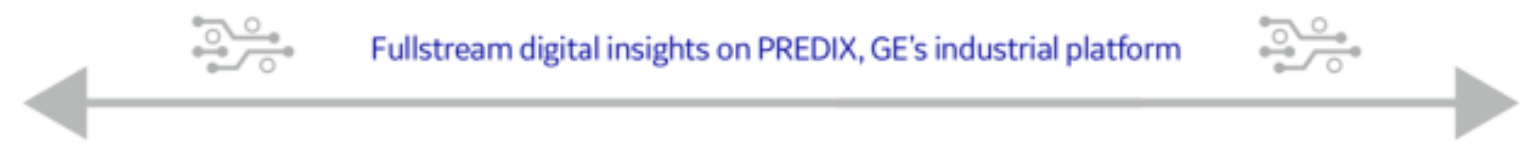

Fonte: BAKER HUGHES, A GE COMPANY (2017)

No momento em que o anúncio foi feito, a BHGE operava em 120 países, tinha um quadro de 70 mil profissionais, 125 anos de experiência no setor e uma receita anual de 17 bilhões de dólares (BAKER HUGHES, A GE COMPANY, 2017).

Ainda naquele momento, a empresa já era dona de, aproximadamente, 22,2\% do mercado global, atrás apenas da Schlumberger com 31\% e Halliburton com 
22,5\% (OWLER, 2019), avaliado em 106 bilhões de dólares (MARKETS \& MARKETS, 2019) e com expectativas de alcançar 330 bilhões em 2026 (BLOOMBERG, 2019).

O grupo escolhido para liderar esse grande player era formado por 14 executivos, 9 dos quais vieram da GE e 5 da antiga Baker, encabeçados por Lorenzo Simonelli, Ex-CEO das GEs Oil \& Gas e Transportation e que havia ocupado diversas outras posições dentro do grupo GE desde 1994.

Embora notem-se diversas vantagens com a formação da BHGE, esse foi e ainda é até hoje um processo extremamente complexo. A integração de duas diferentes culturas centenárias e estruturas organizacionais já estabelecidas em 4 product companies (BAKER HUGHES, A GE COMPANY, 2017) é algo que ainda hoje está em ocorrendo. Se não for feito corretamente, mesmo com o due dilligence prévio, como já notou Mitleton Kelly (2005), a fusão pode terminar em fracasso.

O objetivo desse estudo é entender a estrutura organizacional escolhida para a BHGE e a integração cultural pela qual a empresa passou com o processo de fusão, além de avaliar se os mesmos foram bem sucedidos.

Inicialmente serão descritas teorias acadêmicas sobre os tópicos citados acima, analisando os modelos de estruturas organizacionais, quais se acredita serem mais indicados para o mercado no qual a empresa está inserida e os pensamentos mais correntes sobre cultura organizacional.

Em um segundo momento, será conduzida uma pesquisa qualitativa com os membros da BHGE, além da análise de dados disponibilizados publicamente por ela, essas serão contrapostas às teorias acadêmicas citadas acima.

Por fim, serão apresentadas as conclusões do autor sobre as escolhas feitas pela empresa no momento de sua fusão e recomendações, com base na análise teórica, do melhor caminho para o futuro da BHGE.

Ao analisar o caso da integração estrutural e cultural de uma das maiores empresas de um mercado centibilhonário e que é parte de um conglomerado que há mais de 120 anos está na vanguarda das técnicas de gestão mundiais, espera-se apresentar resultados que possam contribuir para o campo de conhecimento acadêmico do estudo de organizações. 


\section{Revisão da Literatura}

Primeiramente, se faz necessário definir o que são fusão e aquisição (M\&A). Malik, Anuar, Khan e Khan (2014), apresentam diversas definições para os dois conceitos, acabando com qualquer dúvida presente. Abaixo, segue o citado pelos autores:

"'Fusão e aquisição não são a mesma terminologia mas são normalmente usadas como se fossem. Em uma aquisição uma organização compra parte ou o todo de outra organização. Enquanto em uma fusão duas ou mais organizações constituem uma organização (Alao, 2010). Fusão é a atividade legal na qual duas ou mais organizações se combinam e apenas uma sobrevive como entidade legal (Home and John, 2014). Pela definição de Georgios (2011), em uma fusão, duas ou mais firmas se unem e se tornam uma firma única, enquanto em uma aquisição uma firma grande e financeiramente saudável compra uma firma menor. Khan (2011), apresenta a definição de fusão como duas ou mais firmas que se aproximam e formam uma ou mais firmas. Durga, Rao e Kumar (2013), definiram fusões e aquisições como atividades envolvendo takeovers, reestruturações coorporativas, ou controle coorporativo que muda em estrutura de propriedade das firmas". (MALIK, ANUAR, et al., 2014, tradução nossa).

Com as definições claras, segue-se para apresentação de estudos que buscam compreender quais aspectos geram fusões e aquisições bem ou malsucedidas. Embora tenham-se sido gasto, entre 2008 e 2018, aproximadamente 35,63 trilhões de dólares americanos com esses processos (STATISTICA, 2019), quase $65 \%$ deles resutam em perda de valor para o acionista (Marcum, 2003, apud Kelly, 2005 , p. 2), em $70-80 \%$ dos casos as sinergias imaginadas não são de fato alcançadas (Coffey, J., Garrow, V. and Holbeche L. 2003, apud Kelly, 2005, p. 2) e funcionários e clientes são esquecidos (Delloite e Touche, 2001, apud Kelly, 2005, p. 2). 
Gráfico 1: Valor gasto anualmente em fusões e aquisições

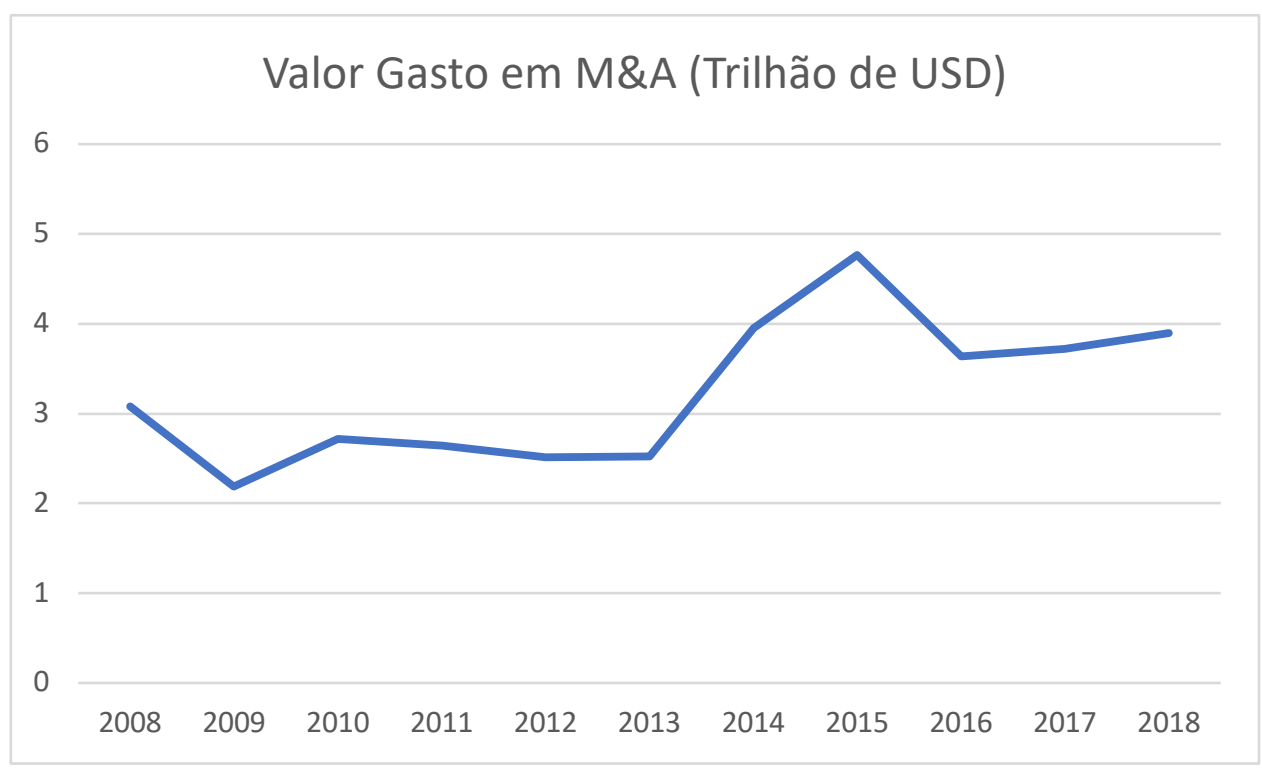

Fonte: Elaboração própria com dados de Statistica (2019)

Em seu artigo, Kelly (2005) concluiu que grande parte das empresas falha em alcançar uma fusão ou aquisição bem sucedida, pois as lideranças encarregadas não colocam ênfase suficiente no que ele chama de relações pós união, e no desenvolvimento de uma cultura integrada para a nova organização.

Seguindo a mesma linha de Kelly, em seu livro sobre fusões e aquisições, Weber, Tarba e Oeberg (2013), página 4 indentificaram os principais fatores para que esses processos resultem, normalmente, em falha. Eles citam:

\footnotetext{
"A principal razão para falhas vem do fato de que é fácil comprar mas difícil realizar uma fusão ou aquisição. Em geral, muitas são caracterizadas pela falta de planejamento, sinergias limitadas, diferenças em cultura de gestão/organizacional/internacional, erros na negociaçãoe dificuldades de implementar a estratégia depois da escolha incorreta da integração pelas organizações sendo fundidas após a assinatura do contrato. A maior parte dos fatores que causam essas falhas indica uma falta de conhecimento pelo lado da alta administração de ferramentas de gestão que permitem lidar com os conhecidos problemas de fusões e aquisições".
}

Como se pode perceber, ambos os autores citam a falta de uma estratégia de integração cultural e estrutural como alguns dos fatores mais relevantes para que o processo de fusão e aquisição acabe em fracasso. Para poder se aprofundar mais no tema, serão resgatadas as definições dos já citados tópicos. 
Na visão de de Robbins, Judge e Sobral (2011), pode se definir a cultura organizacional como "um sistema de valores compartilhados pelos membros de uma organização que a diferencia das demais". Em sua opinião, a cultura disitingue as organizações e gera uma sentimento de identidade para seus membros. Os autores citam também sete características das culturas que existem em um contínuo, podendo ser mais forte ou mais fraca dentro de determinada organização, são eles: inovação, atenção aos detalhes, orientação para resultados, foco na pessoa, foco na equipe, agressividade e estabilidade.

Chiavenato (2010) segue a mesma linha e apresenta uma definição semelhante, para ele, a cultura organizacional é o "conjunto de hábitos e crenças, estabelecidos através de normas, valores, atitudes e expectativas compartilhadas por todos os membros da organização".

Já Aques (1951, p.251) vê o mesmo conceito como:

"Hábito tradicional e costumeiro de pensar e fazer as coisas, que é compartilhado em maior ou menor grau pelos seus membros e que os novos membros devem aprender e assimilar, pelo menos parcialmente para que possam ser aceitos no contexto da empresa". (AQUES, 1951).

Por último, Wilbert e Cruz (2014, p.2) a veem como:

"À estrutura profunda da organização, fundamentada nos valores, crenças e
suposições dos membros da empresa. Os significados são estabelecidos
através da socialização de uma variedade de identidades grupais que
convergem nos locais de trabalho. A interação reproduz um mundo
simbólico que dá à cultura, ao mesmo tempo, estabilidade e uma base frágil
devido à dependência do sistema de ações e cognições individuais".
(WILBERT e CRUZ, 2014).

Por ser um fator de individualização e reconhecimento das organizações, Chiavenato (2010) escreve que a cultura tem um impacto profundo no seu desempenho, o que suporta as descobertas de Kelly (2015) e Weber, Tarba e Oeberg (2013) sobre seu impacto em fusões e aquisições.

Robbins, Judge e Sobral (2011) trazem mais informações sobre esse impacto. Os autores afirmam que, hoje em dia, as possibilidades de um negócio como o citado acima dar certo está diretamente relacionado com a compatibilidade cultural das empresas. A opinião deles é que esse fato é uma métrica mais 
importante a ser analisada do que as vantagens financerias e quantidade de sinergias que virá da união.

A cultura, porém, não é algo único dentro das organizações. Robbins, Judge e Sobral (2011) afirmam ser comum, além da cultura dominante, o aparecimento de sub-culturas em um número relevante de organizações de grande porte. Essas subculturas surgem para "refletir problemas, situações ou experiências comuns a alguns membros pertencentes a determinados departamentos ou regiões geográficas" (ROBBINS, JUDGE e SOBRAL, 2011).

Esse conjunto de princípios pode também ser aceito em diferentes graus. Em seu livro de 2011, os autores mencionam a existência de culturas fortes, aonde os princípios são fortemente aceitos por seus membros, e fracas, aonde se percebem mudanças constantes em seus valores e normas.

Há diversas formas de perpetuação e ensino da cultura organizacional de uma empresa para seus colaboradores. Robbins, Judge e Sobral (2011) citam os seguintes: a contagem de histórias inspiradoras sobre o passado da empresa, através dessas consegue-se trazer o passado ao presente e justificar o por que de determinadas práticas e processos serem comuns na organização; a realização de rituais, como café da manhã com o CEO, festas de final de ano e retiros de lazer, através destes a empresa reforça seus valores e seus objetivos para com os colaboradores; símbolos materiais, como o uso de uniformes, o espaço físico da empresa e o tamanho e elegância da sede, esses sinalizam para os membros a formalidade da mesma, o grau de importância e de igualdade; por último, os autores trazem também a linguagem, que nada mais é do que o vocabulário próprio da empresa ou do setor no qual ela está inserida.

Como pode-se perceber, a cultura organizacional é um fator fundamental para que se possa entender uma organização (CHIAVENATO, 2010). Ela afeta diversos níveis da mesma, sendo um dos pontos mais importantes a ser analisados quando houver a fusão ou aquisição de duas ou mais empresas (WEBER, TARBA e OEBERG, 2013). Uma cultura forte, fará com que os novos membros da organização se adequem aos valores de forma mais rápida e se sintam parte da mesma, o que vem a gerar melhores resultados (ROBBINS, JUDGE e SOBRAL, 2011). 
Um outro conceito fundamental a ser estudado é o de estrutura organizacional. Robbins, Judge e Sobral (2011) a definem como a forma na qual a empresa distribui, agrupa e coordena suas tarefas. Os autores afirmam também que devem-se ter em mente seis fatores quando se for optar por uma estrutura ogranizacional, são eles: "especialização do trabalho, departamentalização, a cadeia de comando, a amplitude de controle, a centralização e descentralização, e a formalização".

Seguindo a mesma escola de raciocínio, Mintzberg (1995) afirma que ela retrata a divisão do trabalho de maneira clara, mostrando quais as posições que essa organização tem, como elas estão agrupadas e como a autoridade formal flui entre elas. Além disso, Oliveira (1994) afirma que a estrutura formal é aquela que foi planejada pela organização e que é formalmente representada por meio de um organograma.

Os acadêmicos da administração já estudaram e definiram diversos tipos de estruturas organizacionais. O primeiro, chamado estrutura linear, tem baixo grau de departamentalização, grande amplitude de controle, autoridade centralizada, poucos níveis hierárquicos e pouca formalização, esse modelo é mais aplicado às pequenas empresas e, como definiu Chiavenato (2001) é: "a forma mais simples e antiga, pois tem sua origem na organização dos antigos exércitos e na organização eclisiática dos tempos medievais." 
Figura 2: Exemplo de estrutura linear

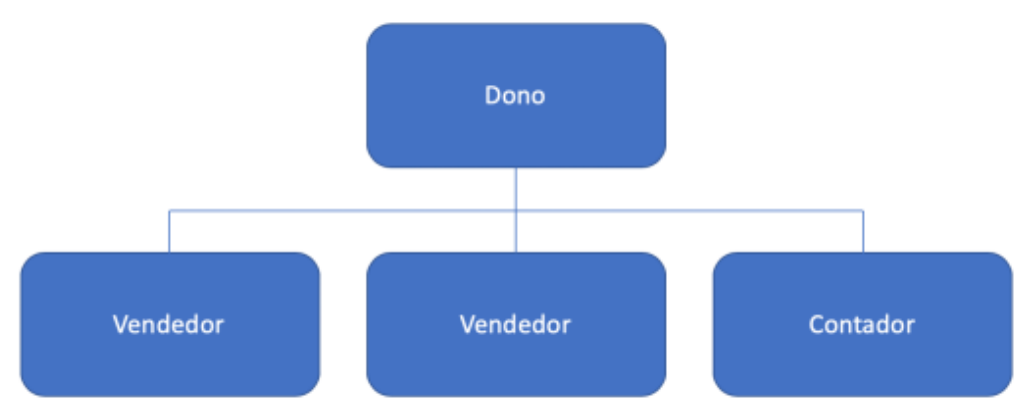

Fonte: Elaboração própria com base nos conceitos apresentados por Chiavenato (2001)

O modelo burocrático, por outro lado, se baseia principalmente no conceito de padronização. Ele é encontrado em grandes empresas e é caracterizado por possuir alta especialização, grande quantidade de departamentalização, autoridade centralizada, baixa amplitude de controle e um processo decisório que acompanha a cadeia de comando. Esse é caracterizado por tarefas rotineiras e alto grau de formalização (ROBBINS, JUDGE e SOBRAL, 2011).

Figura 3: Exemplo de estrutura burocrática

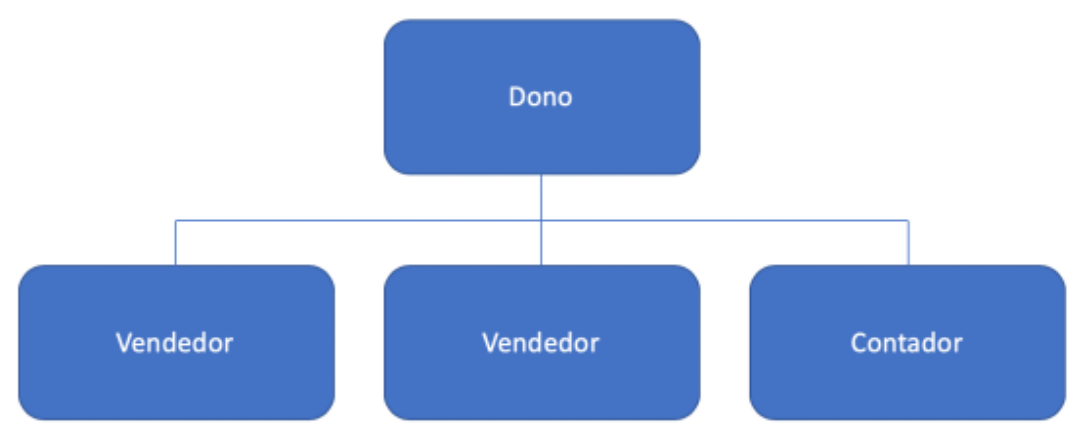

Fonte: Elaboração própria com base nos conceitos apresentados por Robbins, Judge Sobral (2011).

Pode-se citar também o modelo linha-staff, estudado por Chiavenato (2001). Nele, de acordo com o autor:

"coexistem órgãos de linha (órgãos de execução) e de assessoria (órgãos de apoio e de consultoria) mantendo relações entre si. Os órgãos de linha caracterizam-se pela autoridade linear e pelo princípio escalar, enquanto os 
órgãos de staff prestam assessoria e serviços especializados." (CHIAVENATO, 2001, PÁGINA 192)

Esse modelo garante que existam orgãos de assessoria para auxiliar os orgãos de linha na tomada de decisões e execução de suas tarefas.

Figura 4: Exemplo de estrutura linha-staff

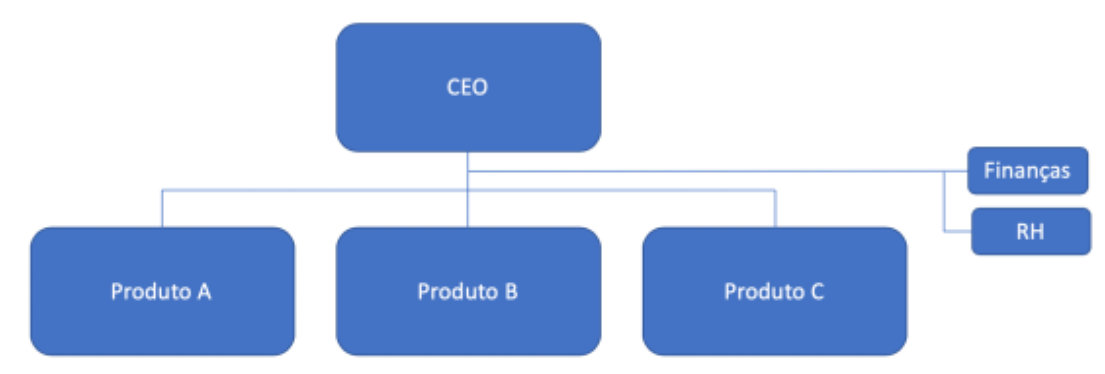

Fonte: Elaboração própria com base nos conceitos apresentados por Chiavenato (2001).

Robins, Judge e Sobral (2011) citam também o modelo de estrutura matricial. Esse combina diferentes tipos de departamentalização tendo uma linha dupla de autoridade. Embora tenha sido pensado para aproveitar os benefícios de diferentes modelos de departamentalização, traz também a desvantagem de, com o fim da unidade de comando, ter dois gestores para cada funcionário, o que pode resultar em confusão por parte do colaborador e em brigas entre os gestores.

Figura 5: Exemplo de estrutura matricial

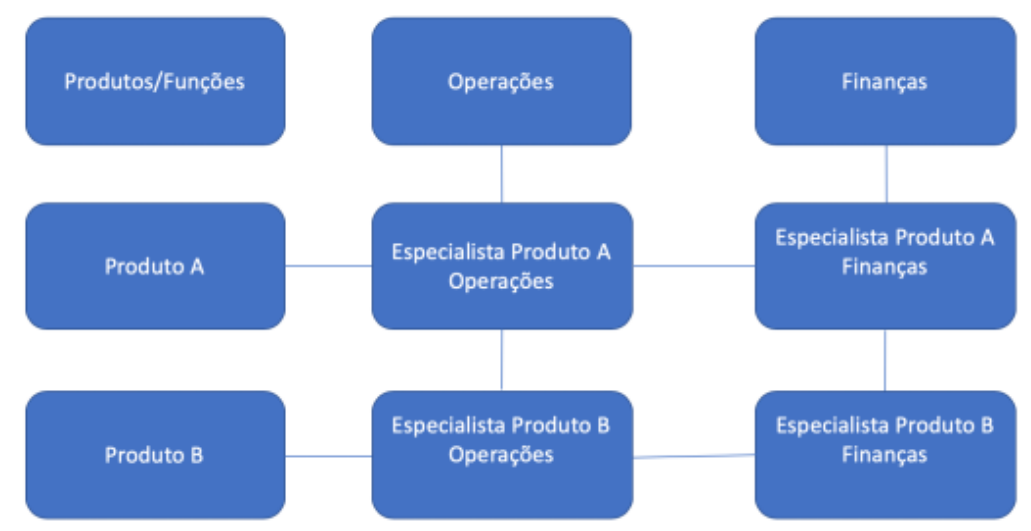

Fonte: Elaboração própria com base nos conceitos apresentados por Robbins, Judge Sobral (2011). 
Por último, Robins, Judge e Sobral (2011) citam também um novo modelo que vem surgindo nos últimos anos, a estrutura em rede. Nesse modelo, a organização foca nas suas atividades essenciais, tercerizando grande parte de suas funções, criando uma rede de fornecedores, clientes e até mesmo concorrentes, e resultando numa estrutura mais enxuta e flúida. Percebe-se também que são formadas equipes multifuncionais, permanentes ou não, para que haja uma união de um amplo leque de conhecimentos a serviço da empresa (SOBRAL e PECI, 2008).

Figura 6: Exemplo de estrutura em rede

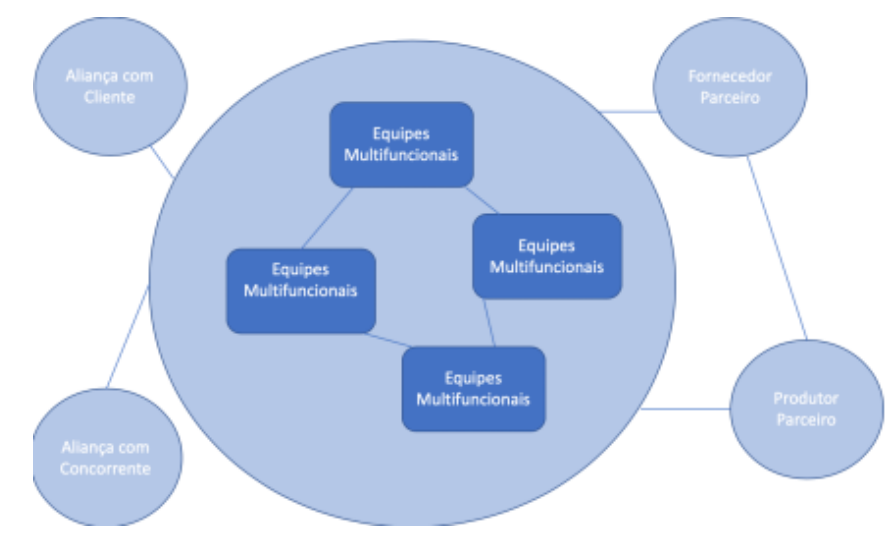

Fonte: Elaboração própria com base nos conceitos apresentados por Robbins, Judge Sobral (2011) e Sobral e Peci (2008).

Esses mesmos autores, indicam que dentro da estrutura organizacional, pode-se perceber diferentes formas de departamentalização. Além disso, dado o crescimento das empresas e a complexidade de suas operações, elas podem assumir diferentes tipos de departamentalização para diferentes níveis.

Em seu livro publicado em 2001, Chiavenato indicou quais seriam os seis principais tipos de departamentalização que uma organização poderia assumir. São eles:

A departamentalização funcional - essa é a mais comum e busca agrupar os recursos da organização por meio do papel que eles desempenham, como financeiro, marketing, entre outros. 
Figura 7: Exemplo de departamentalização funcional

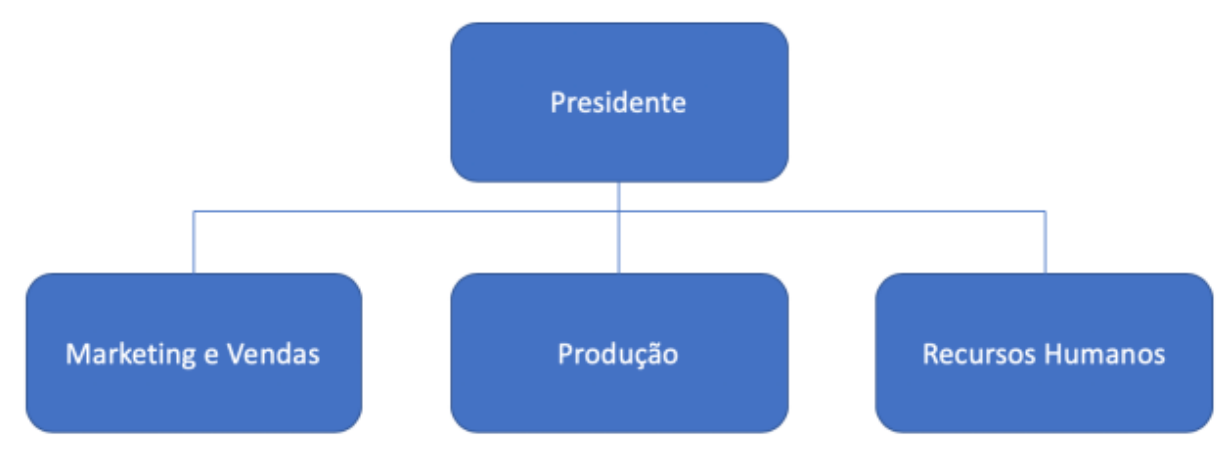

Fonte: Elaboração própria com base nos conceitos apresentados por Chiavenato (2001)

A departamentalização por produtos ou serviços - nesse modelo, a empresa elege dividir seus recursos e atividade de acordo com a produto/serviço produzido por eles. Com isso, a empresa consegue focar em cada um de seus produtos, tendo equipes voltadas especificamente para desenvolvê-los e alcançar os objetivos estabelecidos para os mesmos. Por outro lado, uma grande desvantagem é que os diferentes departamentos tem difícil interação entre si, prejudicando sua comunicação e integração.

Figura 8: Exemplo de departamentalização por produtos/serviços

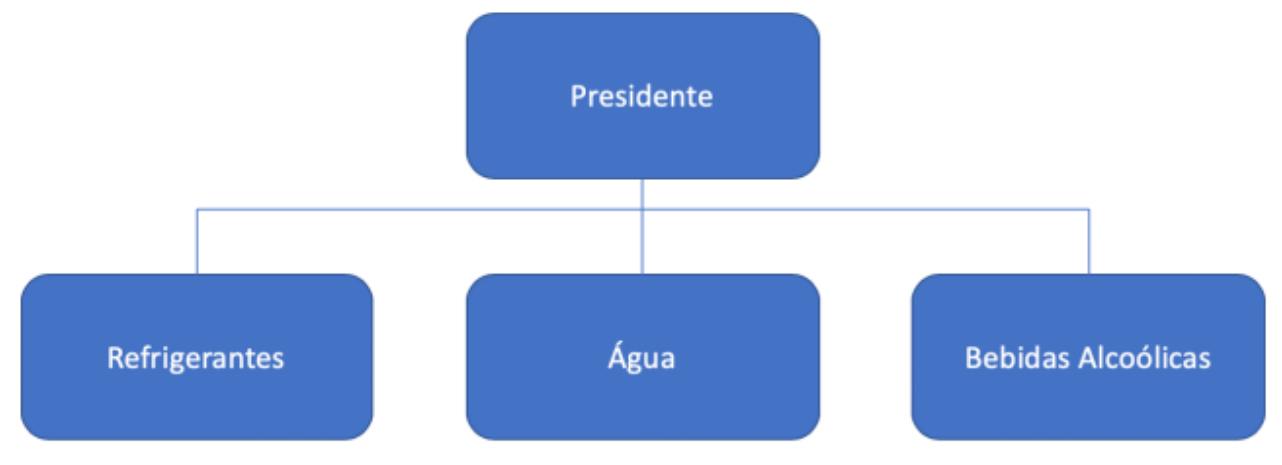

Fonte: Elaboração própria com base nos conceitos apresentados por Chiavenato (2001)

A departamentalização por localização geográfica - Essa opção é utilizada por empresas que atuam em diferentes regiões geográficas e escolhem se departamentalizar com base nos locais aonde atua, é muito comum em multinacionais que operam em uma larga gama de países. 
Figura 9: Exemplo de departamentalização por localização geográfica

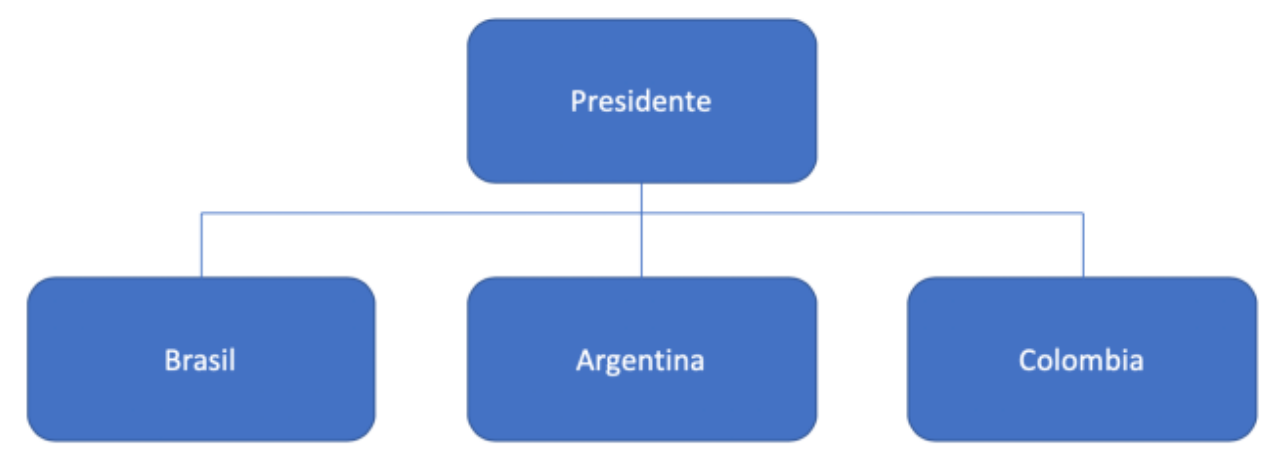

Fonte: Elaboração própria com base nos conceitos apresentados por Chiavenato (2001)

Departamentalização por clientes - Empresas que atuam em segmentos vastos e tem um largo leque de clientes que são diferentes entre si, escolhem essa opção de departamentalização.

Figura 10: Exemplo de departamentalização por clientes

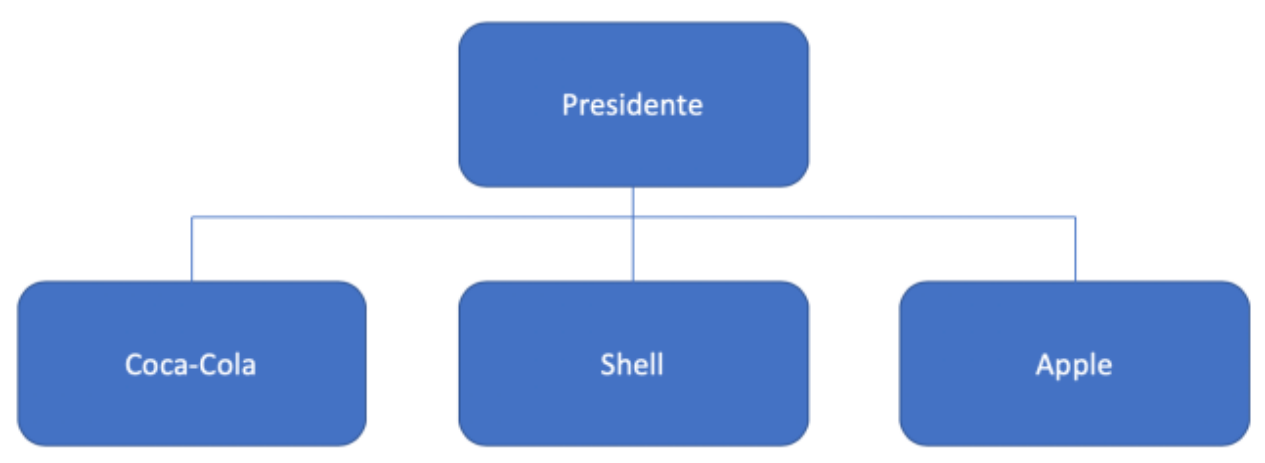

Fonte: Elaboração própria com base nos conceitos apresentados por Chiavenato (2001)

Departamentalização por fase do processo - A organização escolhe agrupar suas atividades por fase do processo produtivo, é mais comum no nível operacional e em fábricas. 
Figura 11: Exemplo de departamentalização por fase do processo

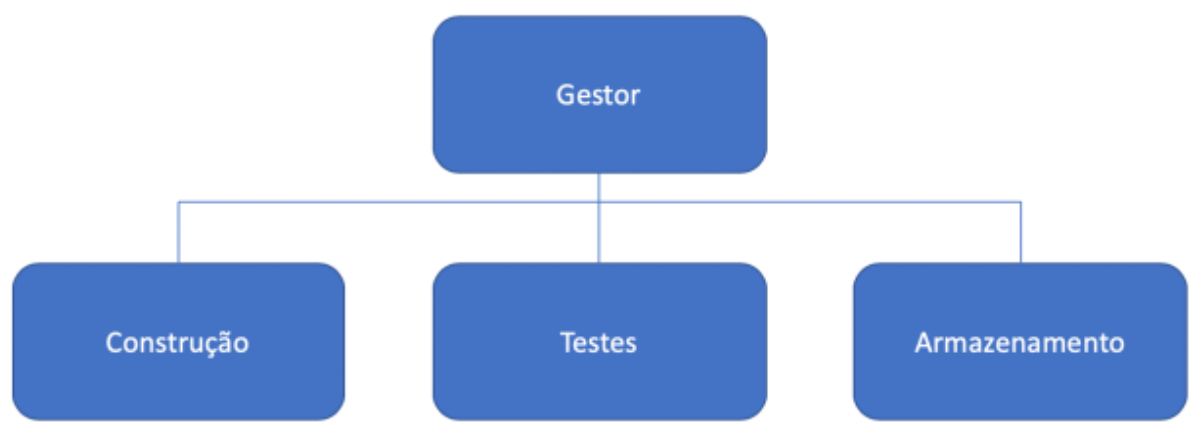

Fonte: Elaboração própria com base nos conceitos apresentados por Chiavenato (2001)

Departamentalização por projetos - requer uma estrutura flexível e divide os recursos e atividades da empresa com base no projeto em que estão atuando, como projetos são atividades temporárias essa forma de departamentalização é altamente mutável.

Figura 12: Exemplo de departamentalização por projetos

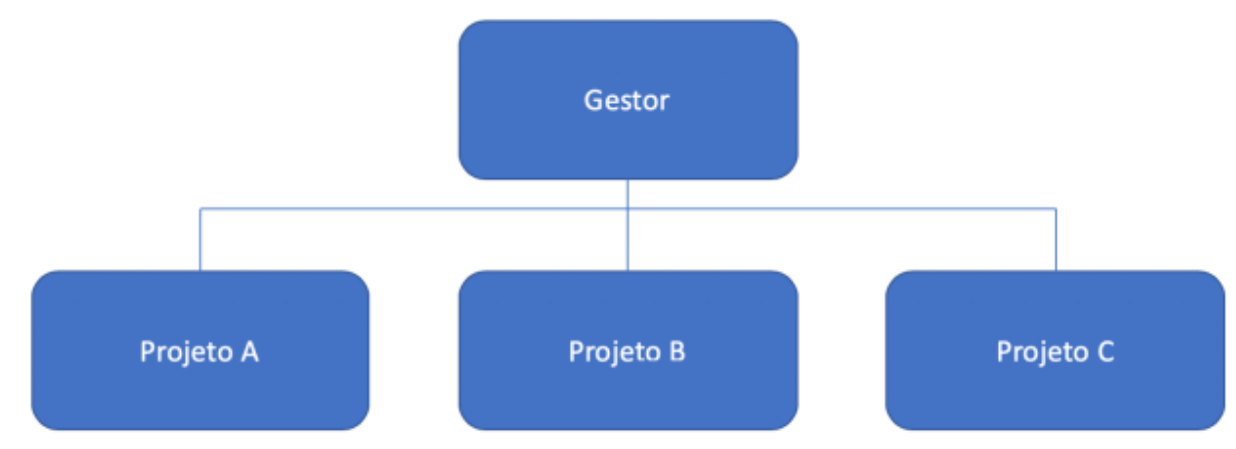

Fonte: Elaboração própria com base nos conceitos apresentados por Chiavenato (2001)

A escolha de um ou mais tipos de departamentalização influenciam diretamente no resultado da empresa e é uma das decisões com maior impacto no momento de estruturar uma organização, especialmente uma que é o resultado de uma fusão ou aquisição (ROBBINS, JUDGE e SOBRAL, 2011). Em seu artigo, Kelly (2005) concorda com os autores ao também indicar que a falha em definir funções, responsabilidades e incentivos além de uma estrutura opaca são alguns dos 
principais fatores que levam ao insucesso desses processos (Delloite e Touche, 2001, apud Kelly, 2005, p. 2). 


\section{Apresentação das Empresas}

Antes de explicitar a metodologia de pesquisa e analisar os resultados, faz-se necessário apresentar a empresa que será analisada, além de suas originárias.

A história da General Electric começa em 1876, em um pequeno laboratório em Menlo Park, New Jersey. Esse laboratório foi aberto por Thomas Edinson que, 3 anos mais tarde, anunciaria a criação de uma tecnologia revolucionária: a lâmpada incandescente (OWLES, 2017).

Figura 13: Lampada incandecente inventada por Thomas Edinson

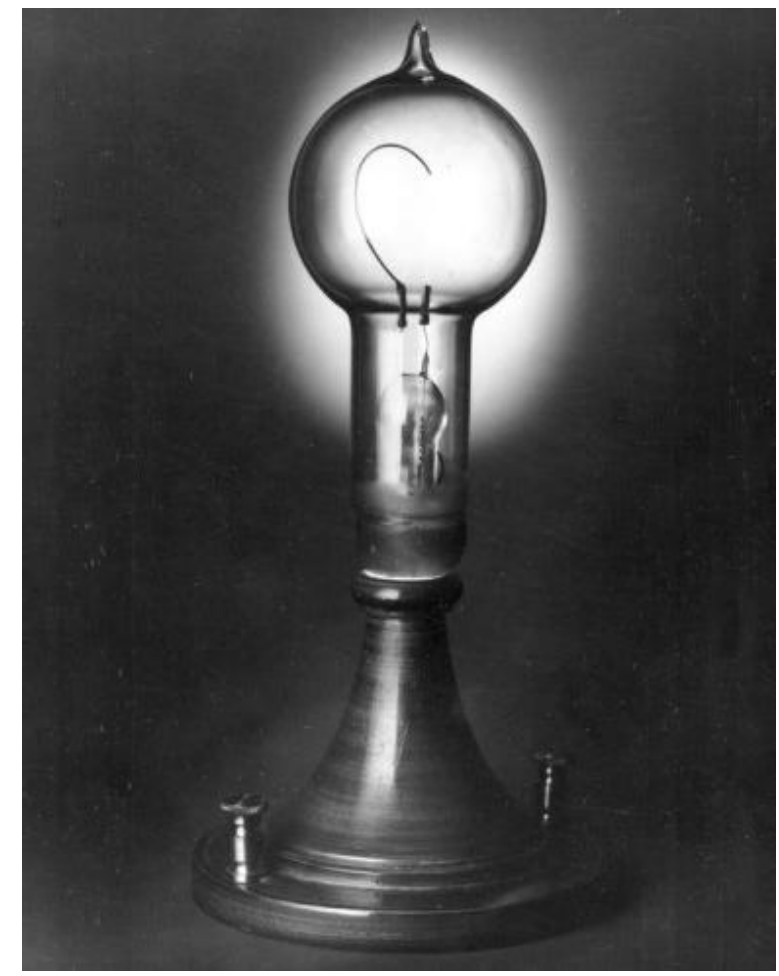

Fonte: The New York Times (2017)

Essa uma das mais importantes criações do homem que, em 1890, uniria seus vários negócios em uma só empresa, a Edinson General Electric que, dois anos mais tarde, seria renomeada como General Electric (GE) (GENERAL ELECTRIC, 2019). 
Figura 14: Evolução dos logos da General Electric (1891-2019)

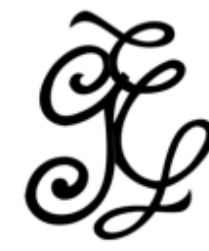

1891-1900

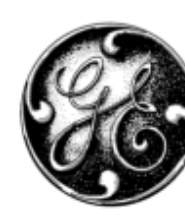

1900-1934

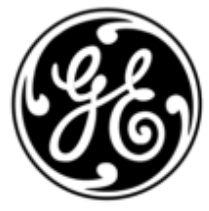

1934-1970
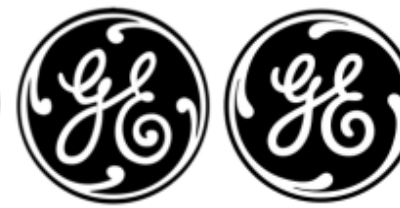

1970-1986

1986-2002
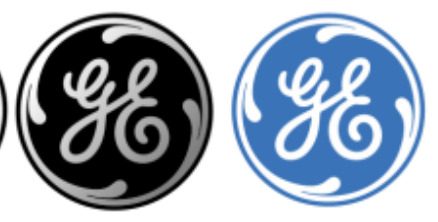

2002-2004 2004-present

Fonte: INPHANTRY (2012)

O espírito empreendedor de Edinson fez com que desde cedo a empresa operasse em diversos segmentos: em 1890 a GE Appliances começou a produzir ventiladores e em 1907 fogões, em 1987 a GE começou a desenvolver motores de avião, em 1893 ela já possuia locomotivas a vapor e 1896 máquinas de raio-x (OWLES, 2017).

Em seus mais de 120 anos, a GE passou por diversas mudanças tendo seu ápice sob a tutela de Jack Welch, entre 1981 e 2001. Com a pessoa considerada o gestor do século pela revista Fortune (COLVIN, 1999) no controle, a GE alcançou em agosto de 2000, 601 bilhões de dólares em valor de mercado (BLOOMBERG, 2019).

A estratégia de Welch se centrava em crescimento acelerado e maximização do valor para os acionistas. Para isso, "Neutron Jack", como ficou conhecido no mercado, fez mais de 900 aquisições e 400 vendas, ele mantinha e comprava apenas empresas que eram a $1^{\mathrm{a}}$ ou $2^{\mathrm{a}}$ colocadas de suas indústrias (HARTUNG, 2017), divesificando seu portfólio que ia desde a aviação até a indústria de entretenimento (BLOOMBERG, 2019).

Para sustentar sua estratégia de crescimento acelerado, ele incentivava uma cultura na qual cada funcionário era um líder de seu próprio mini-negócio, investiu pesadamente em educação executiva e implementou a política conhecida como conserte, feche ou venda, na qual empresas que não alcançavam o esperado tinham que ser consertadas no curto-médio prazo, eram fechadas ou vendidas (MURRAY, 2001). 
Suas estratégias, apesar de vistas por muitos como radicais, traziam resultados. Comparando o ano em que assumiu a presidência (1981) com quando deixou a GE (2001), a empresa teve os seguintes resultados: redução de $22 \%$ do quadro de funcionários (MURRAY, 2001), lucros passaram de 1,5 bilhões para cerca de 12,7 bilhões de dólares (MURRAY, 2001), receitas brutas quintuplicaram (MURRAY, 2001), valorização das ações em 5.096\% (MURRAY, 2001), 350\% a mais do que o índice Down Jones no mesmo período (HARTUNG, 2017), entre outras.

Após sua saída, a GE passou por 3 CEOs e entrou em uma crise ainda sem fim. Hoje, a GE tem o valor de mercado de 82 bilhões (YAHOO FINANCE, 2019), $14 \%$ do seu pico sob a tutela de Jack Welch e passa por uma enorme reestruturação, baseada em um plano de desenvestimento desenhado pelo CEO atual, Larry Culp (GRYTA, 2019) e que verá a GE vender, entre outros ativos, sua participação na BHGE, que voltará a ser uma empresa independente mas agora com o portfólio de produtos da antiga GE Oil \& Gas (GRYTA, 2019).

Embora esteja hoje saindo do mercado de óleo e gás, a GE começou a operar nessa indústria em 1994. Ainda com Jack Welch, a aquisição da italiana fabricante de turbinas e turbo compressores Nuovo Pignone iniciou um investimento de 14 bilhões de dólares no setor, criando um portfólio de produtos e serviços tão largo que em 2016 a empresa elegeu separar o segmento, até então parte da GE Energy, em uma entidade legal própria, a GE Oil and Gas (GENERAL ELECTRIC, 2017). 
Figura 15: Investimento da GE no setor de óleo e gás (1994-2015)

\section{\$14B+ invested 30+ acquisitions}

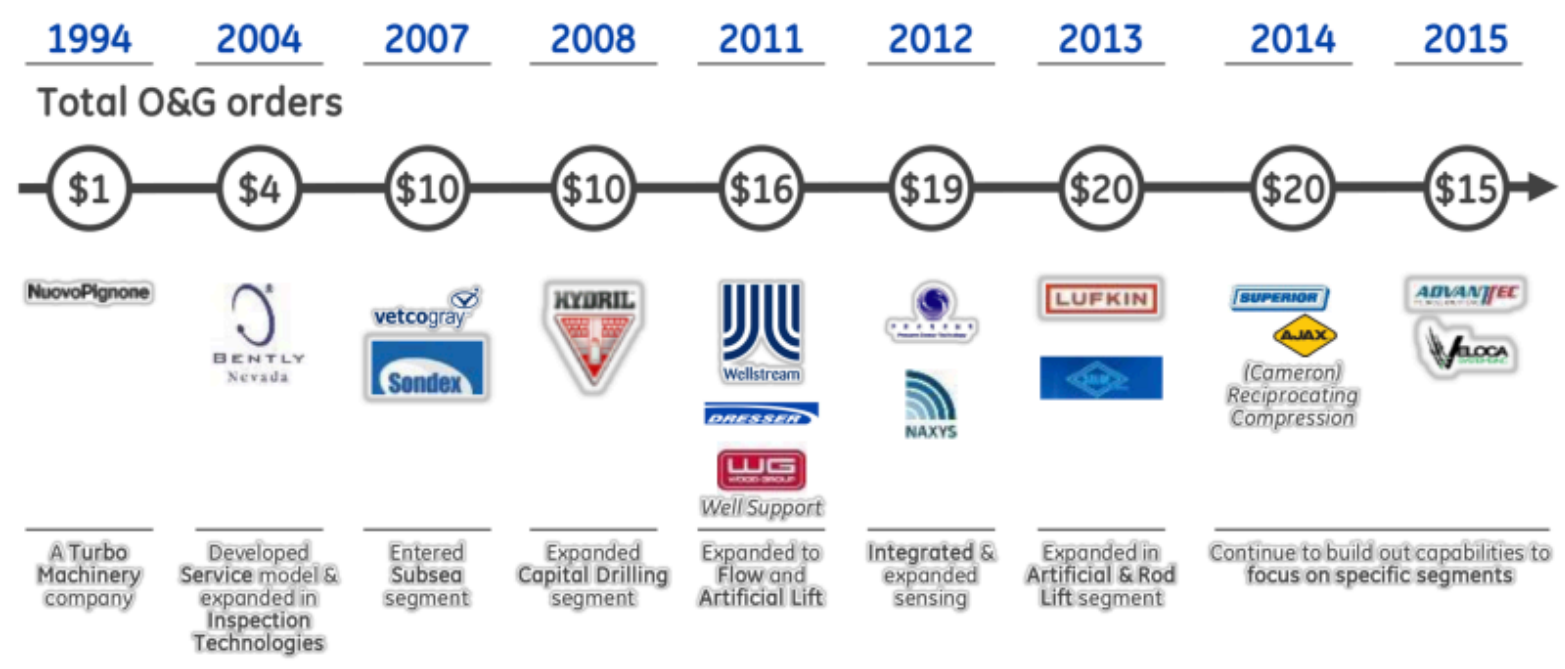

Fonte: General Electric (2017)

O comando da nova empresa, que tinha sede em Londres, foi confiado a Lorenzo Simonelli, um executivo senior que tinha, até então 21 anos de experiência na GE. Ela foi estruturada ao redor de suas 5 linhas de produto: Turbo Machinery Solutions, Digital Solutions, Surface, Subsea Systems \& Drilling e Downstream Technology Solutions. Logo em seu primeiro ano a empresa teve cerca de 16 bilhões de dólares em receitas (GENERAL ELECTRIC, 2017). 
Figura 16: Linhas de Produto da GE Oil \& Gas

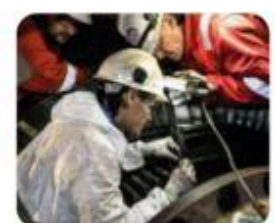

TURBOMACHINERY SOLUTIONS

- Gas turbines

- Axial \& centrifugal

compressors

- Electric motor-

driven

compressors

- Turboexpanders

and heat

exchangers

- Modular LNG

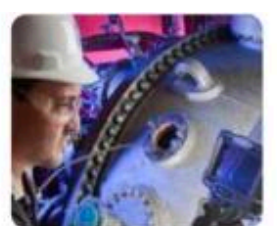

DIGITAL SOLUTIONS

- Asset / vibration

monitoring

- Pipeline integrity \&

inspection

- Non-destructive

testing equipment \&

services

- Flow meters

- Installed sensing

- Leak detection

- Nuclear instrument

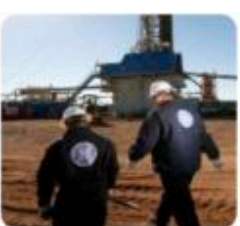

SURFACE

- Rod lift systems

- Electrical

submersible

pumps

- Downhole tools

- Surface

wellheads

- Logging services

- Service and

repair

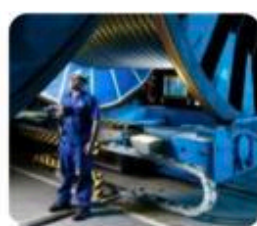

SUBSEA SYSTEMS \& DRILLING

-Subsea trees \&

wellheads

- Subsea power \&

processing

- Manifolds

- Flexible risers \&

flow lines

- BOPs

- Drilling systems

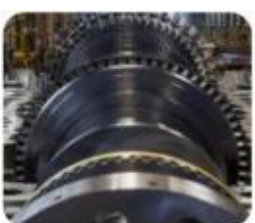

DOWNSTREAM TECHNOLOGY SOLUTIONS

-Steam turbines

- Recip.

compressors

- High-speed

recip.

compressors

- Pumps, valves

and fuel gas

systems

Fonte: General Electric (2017)

Ao mesmo tempo em que a GE estava aumentando os investimentos no mercado, uma grande oportunidade surgia. Em $1^{\circ}$ de maio de 2016, a Halliburton, $2^{\mathrm{a}}$ maior empresa do setor, anunciou que havia desistido de adquirir a Baker Hughes, $3^{a}$ maior, como havia sido planejado 2 anos antes (HALLIBURTON, 2016). A união, que formaria a maior empresa de serviços de óleo e gás do mundo, com 50 bilhões de dólares em receitas anuais, 136 mil empregados e operação em 80 países havia sido anunciada em novembro de 2014 por 34 bilhões de dólares (HALLIBURTON , 2014). O negócio não foi a frente pois o departamento de justiça norte-americano abriu diversos processos anti-truste contra as empresas (U.S. DEPARTMENT OF JUSTICE, 2016).

Com o fim da perspectiva de ser adquirida pela Halliburton, a Baker estava novamente disponível para ser adquirida.

A Baker Hughes, uma empresa centenária, é o resultado da fusão entre a Baker Oil Tool Company (fundada em 1907) e a Hughes Tool Company (fundada em 1909) (COMPANIES HISTORY, 2019), e uma das líderes de seu setor. Em 2016 ela operava em 80 países e tinha 33 mil colaboradores ao redor do mundo, a mesma focava seus produtos/serviços no setor de perfuração de poços de petróleo (BAKER HUGHES, 2016). 
A empresa era estruturada em 4 divisões regionais: North America, Latin America, Europe/Africa/Russia Caspian, e Middle East/Asia Pacific que respondiam a seu presidente de operações globais e era liderada pelo CEO Martin Craighead (BAKER HUGHES, 2016).

Embora fosse um gigante do setor, ela passava por um grande crise. Suas receitas, que haviam chegado a 24 bilhões de dólares em 2014, tinham crescido constantemente desde 2009 e não ficavam abaixo de 20 bilhões desde 2012, foram de apenas 9 bilhões em 2016 (BAKER HUGHES, 2016) (BAKER HUGHES, 2012). Essa queda brusca se deu pela queda na perfuração de novos poços, aonde a Baker tinha todo o seu portfólio de produtos, ao redor do mundo, influenciados pela forte diminuição de preços do petróleo no mercado internacional (TREFIS TEAM, 2015).

Observando o potencial da marca e a conjuntura da época, a GE se moveu rapidamente para adquirir la. Em 31 de outubro de 2016, 6 meses após a desistência da Halliburton, a GE e a Baker Hughes anunciaram planos para que a última fosse adquirida pela primeira e fundida a sua subsidiária GE Oil \& Gas (GENERAL ELECTRIC, 2016).

Menos de um ano depois, no dia 3 de julho de 2017, a General Electric anunciou oficialmente a aquisição da Baker Hughes e a fusão da mesma com a já existente GE Oil \& Gas (BAKER HUGHES, A GE COMPANY, 2017). O resultado dessa união passou a ser conhecido como Baker Hughes, a GE Company (BHGE), uma empresa que tem $62,5 \%$ do seu capital controlado pela GE e 37,5\% trocado publicamente na bolsa de Nova lorque (HAMPTON e SCHEYDER, 2017). 
Figura 17: Resumo do negócio entre GE e Baker Hughes

\section{Transaction Overview...}
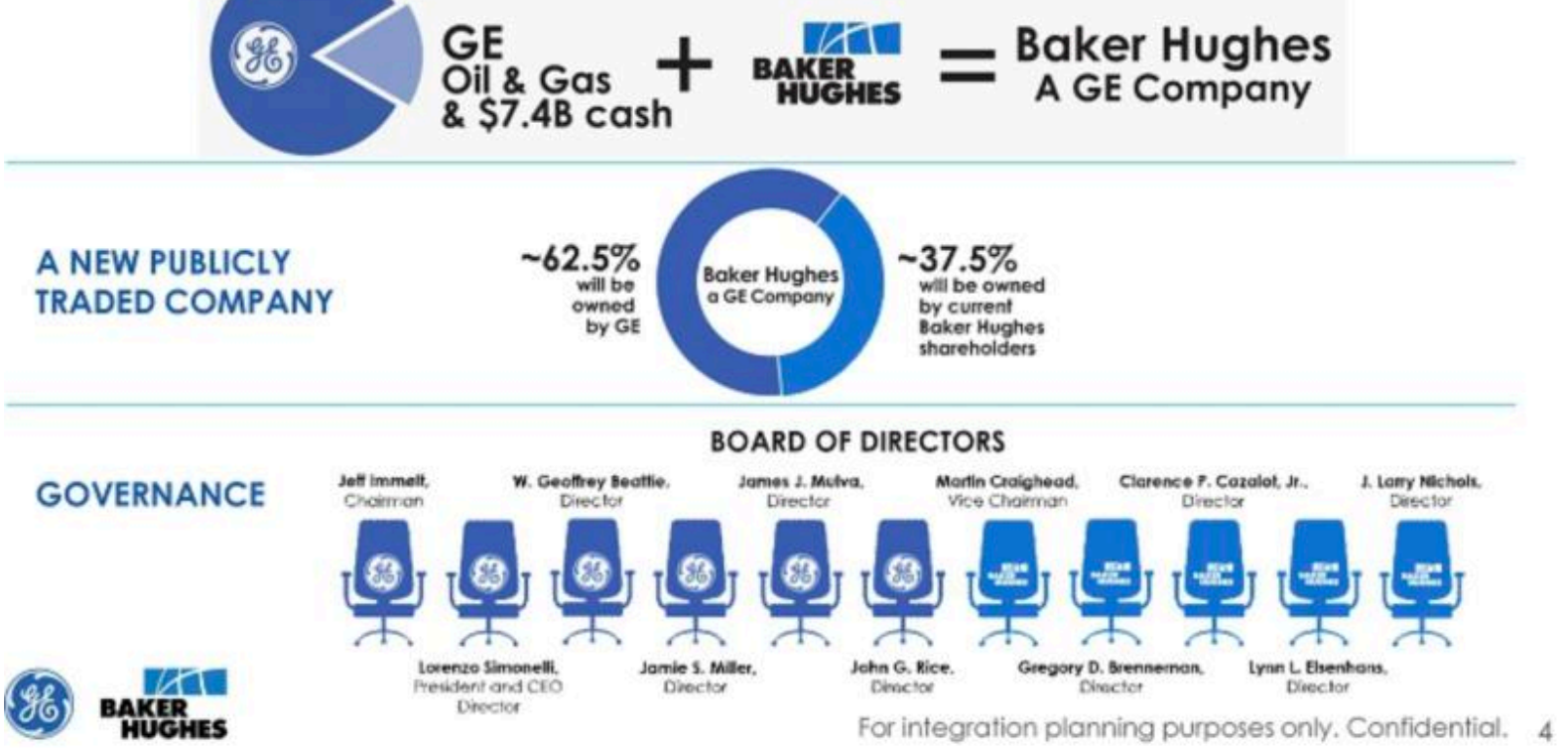

Fonte: Baker Hughes (2017), apud SEC (2017)

Com a união de seus portfólios, a BHGE passou a operar em um modelo de negócio fullstream. Dessa forma, atuando em toda a cadeia de valor do setor e agregando o uso de novas tecnologias, ela conseguiria uma vantagem competitiva pois teria economias de escala e conseguiria vender projetos de soluções completas e integradas para seus clientes.

Figura 18: Breakdown da cadeia de valor fullstream

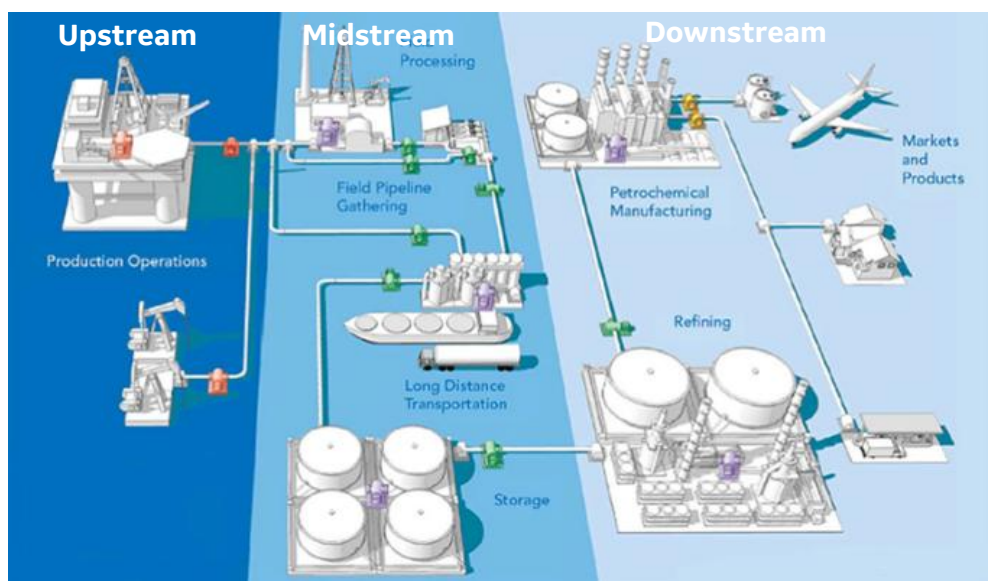

Fonte: BAKER HUGHES, A GE COMPANY (2017) 
No momento em que o anúncio foi feito, a BHGE operava em 120 países, tinha um quadro de 70 mil profissionais, 125 anos de experiência no setor e uma receita anual de 17 bilhões de dólares (BAKER HUGHES, A GE COMPANY, 2017).

Figura 19: Resultado da fusão entre Baker Hughes e GE Oil \& Gas

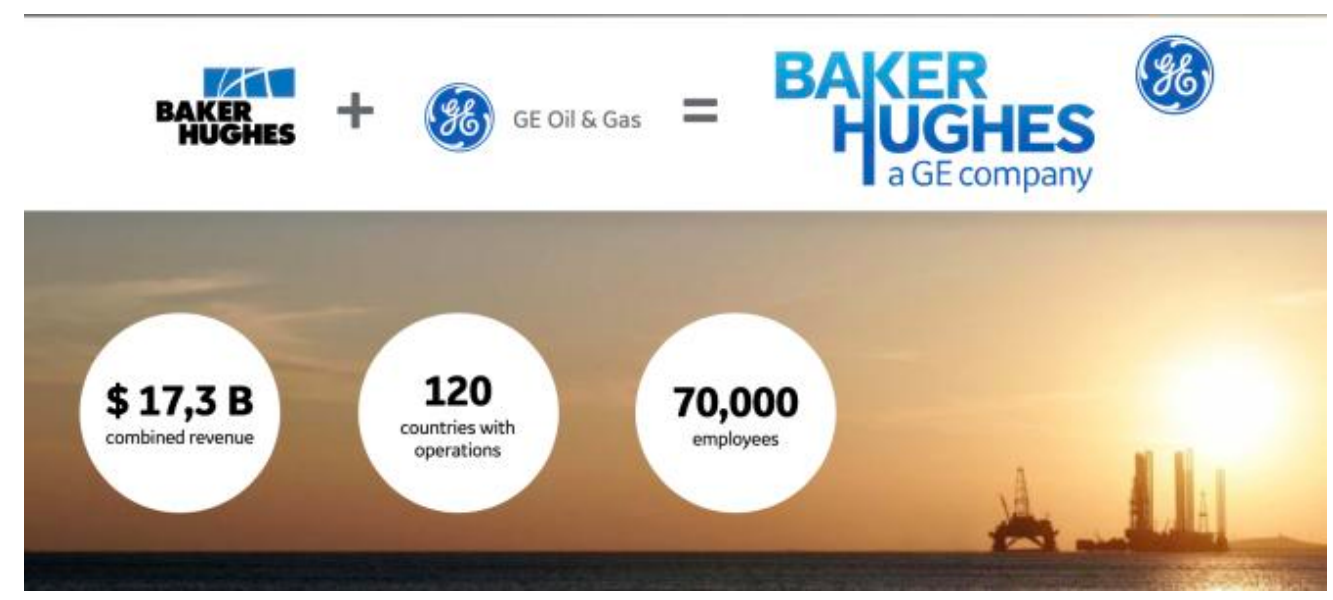

Fonte: BAKER HUGHES, A GE COMPANY (2017)

O grupo escolhido para liderar esse grande player era formado por 14 executivos, 9 dos quais vieram da GE e 5 da antiga Baker, encabeçados por Lorenzo Simonelli, Ex-CEO das GEs Oil \& Gas e Transportation e que havia ocupado diversas outras posições dentro do grupo GE desde 1994.

A nova empresa foi estruturada, a nível global, em um modelo de linha-staff com 4 product lines: Turbomachinery and Process Solutions (TPS), Oil Field Equipment (OFE), Oil Field Services (OFS) e Digital Solutions. Dessas quatro, TPS, OFE e Digital Solutions vinham da GE e OFS vinha da Baker (BAKER HUGHES, A GE COMPANY, 2017); e as áreas funcionais de staff, como finanças, $\mathrm{RH}$ e tecnologia da informação dando suporte. 
Figura 20: Estrutura Organizacional da BHGE

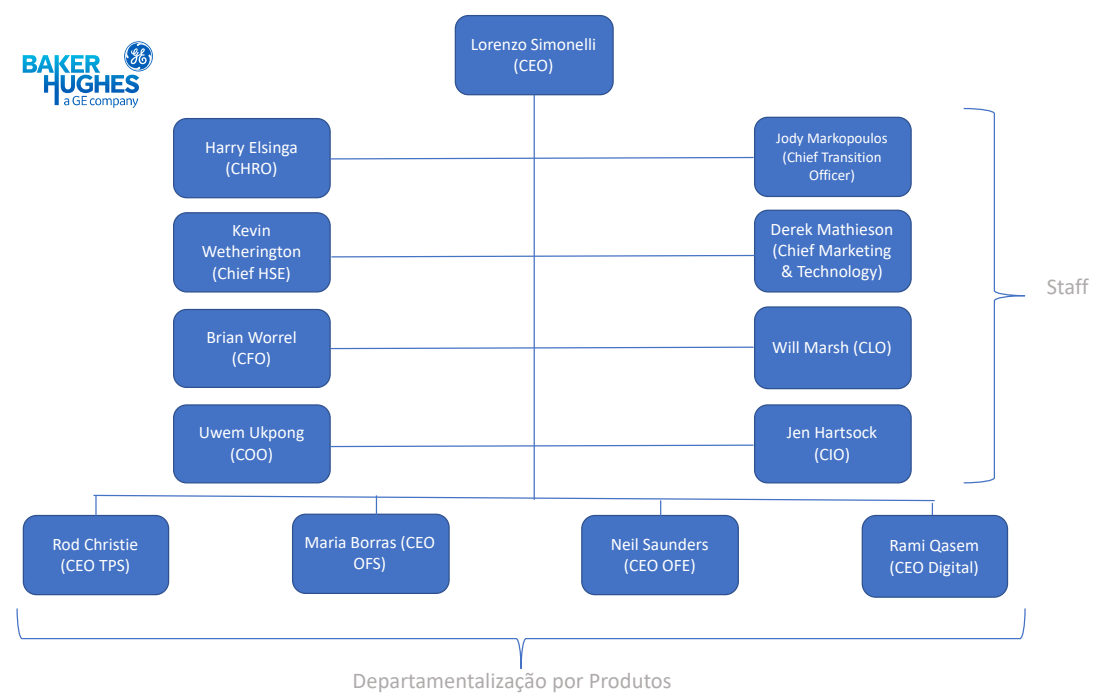

Fonte: Elaboração própria com dados apresentados pela BAKER HUGHES, A GE COMPANY (2019)

Saindo do nível global, cada product line é estruturada matricialmente. Usando como critério as departamentalizações geográficas e por serviços, a ideia é montar uma estrutura de equipes multidisciplinares que adaptem rápido as mudanças e consigam lidar com as demandas dos seus clientes.

Figura 21: Estrutura Organizacional das product lines da BHGE

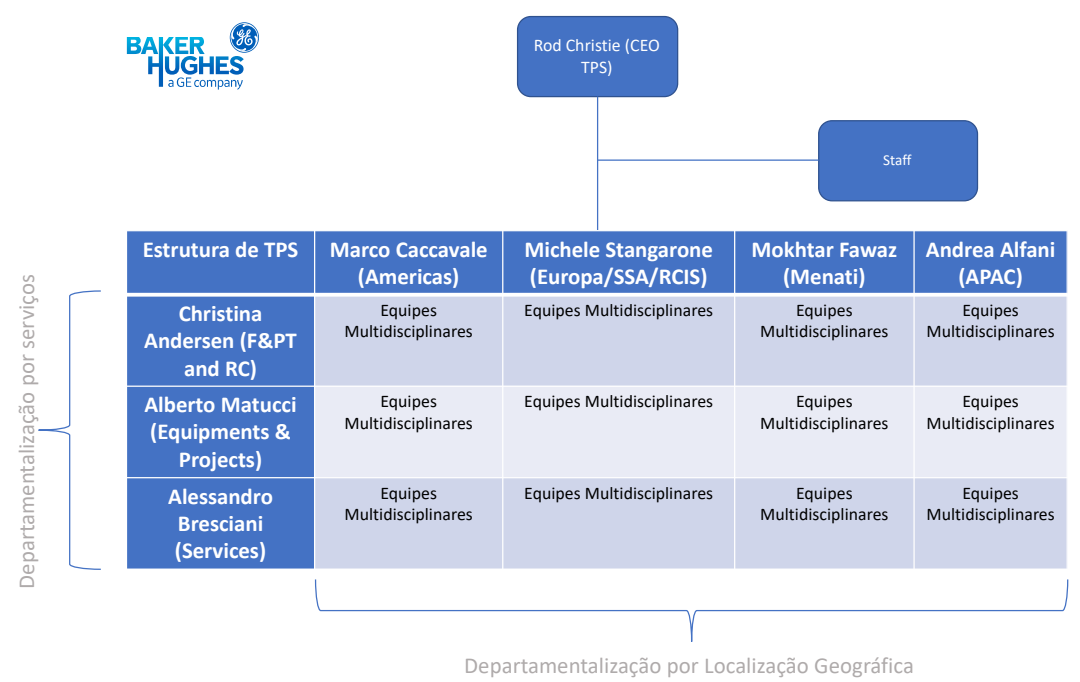

Fonte: Elaboração própria com dados apresentados pela BAKER HUGHES, A GE COMPANY (2019) 
Em relação à cultura organizacional, a GE escolheu por criar uma nova cultura na BHGE fortemente baseada na sua. Desde a mudança da identidade visual, que recebeu a mesma tonalidade de azul e fonte usada pela GE, além do logo da mesma, passando pelos valores, chamados de pilares culturais e derivados dos GE Beliefs, o abandono de grande parte dos sistemas utilizados pela Baker e adoção dos utilizados pela GE, a liderança escolhida e, entre outros, a realocação dos funcionários, em sua maior parte, para escritórios GE; mostram que a nova empresa seria uma extensão da GE e que os colaboradores da Baker teriam que ser adaptar.

Figura 22: Pilares culturais da BHGE

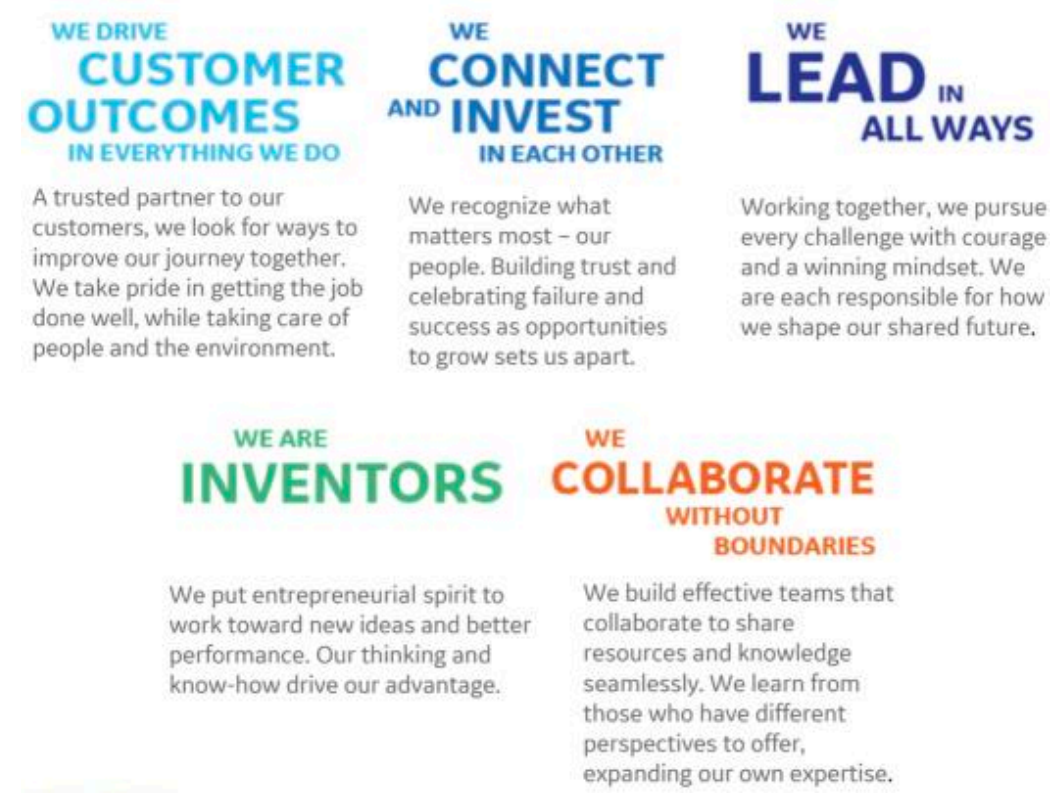

Fonte: BAKER HUGHES, A GE COMPANY (2019)

Já naquele momento, a empresa era dona de, aproximadamente, $22,2 \%$ do mercado global, atrás apenas da Schlumberger com 31\% e Halliburton com 22,5\% (OWLER, 2019), avaliado em 106 bilhões de dólares (MARKETS \& MARKETS, 2019) e com expectativas de alcançar 330 bilhões em 2026 (BLOOMBERG, 2019).

Em 2018, mesmo com uma queda de $24,84 \%$ no preço do petróleo no ano (MACRO TRENDS, 2019), a BHGE reportou uma receita de 22,9 bilhões de dólares, um aumento de $32,37 \%$, e um aumento de $62 \%$ no lucro operacional comparado a 
2017 (BAKER HUGHES, A GE COMPANY, 2018). Nesse mesmo ano, com Larry Culp assumindo a presidência da GE, foi anunciado que a empresa sairia nos 3 anos seguintes, como parte de seu plano de desinvestimento, de sua posição na BHGE.

Em 16 de setembro de 2019, a BHGE e a GE anunciaram o acordo para que a primeira recompre 144 milhões de ações próprias que estavam sob o controle da segunda. Com esse movimento a participação da GE cai para $35 \%$ e a Baker Hughes voltará a ser uma empresa independente, agora com todo o portfólio das antigas GE Oil \& Gas e Baker Hughes (BAKER HUGHES, A GE COMPANY, 2019).

Embora o impacto que esse novo movimento de separação terá na estrutura e na cultura organizacional da empresa seja um tema de grande relevância para o campo das organizações, esse estudo não o abordará. Ao invés disso, o objetivo desse estudo é entender a estrutura organizacional escolhida para a BHGE e a integração cultural pela qual a empresa passou com o processo de fusão, além de avaliar se os escolhidos foram bem sucedidos. 


\section{Metodologia de Pesquisa}

\subsection{Introdução à Metodologia}

Para se alcançar o objetivo final desse estudo, será feita uma pesquisa qualitativa com os membros da organização BHGE. De acordo com Gerhardt e Silveira (2019, p.31), esse tipo de pesquisa possue as seguintes características:

"A pesquisa qualitativa não se preocupa com representatividade numérica, mas, sim, com o aprofundamento da compreensão de um grupo social, de uma organização, etc. (...) O objetivo da amostra é de produzir informações aprofundadas e ilustrativas: seja ela pequena ou grande, o que importa é que ela seja capaz de produzir novas informações (DESLAURIERS, 1991).

(...) A pesquisa qualitativa preocupa-se, portanto, com aspectos da realidade que não podem ser quantificados, centrando-se na compreensão e explicação da dinâ- mica das relações sociais."

Para que a pesquisa seja o mais abrangente possível, foram entrevistados 10 colaboradores da empresa, aonde 2 vieram da antiga Baker Hughes, 6 da antiga GE Oil \& Gas e 2 entraram após a fusão, sendo BHGE desde o início de suas trajetórias na empresa.

Com a autorização do RH da empresa, os entrevistados foram contatados e todos se mostraram disponíveis para conversar, com alguns recomendando e chamando outros entrevistados. O processo ocorreu dentro de um período de 3 dias entre o primeiro contato até o final da última entrevista e os entrevistados foram selecionados com base na proximidade com o autor e os níveis organizacionais ocupados por eles.

\subsection{Perfil dos Entrevistados}

Dentre os entrevistados, $80 \%$ eram homens brancos, $10 \%$ homens negros e $10 \%$ mulheres negras, $80 \%$ eram brasileiros e $20 \%$ italianos e o tempo médio de casa foi de 7,7 anos e variou desde 1,5 anos até 20 anos. 
Tabela 1: Perfil dos Entrevistados

\begin{tabular}{|c|c|c|c|c|c|}
\hline Nome & Idade & Sexo & Contratado Por & Tempo de Casa (anos) & Posição \\
\hline Entrevistado 1 & 23 & $\mathrm{M}$ & BHGE & 1,5 & Estagiário de Parts Management \\
\hline Entrevistado 2 & 37 & $\mathrm{M}$ & GE Oil \& Gas & 7 & Installation Manager \\
\hline Entrevistado 3 & 30 & $\mathrm{~F}$ & Baker Hughes & 9 & Analista de Exportação \\
\hline Entrevistado 4 & 25 & $\mathrm{M}$ & Baker Hughes & 2 & Assistente de Regimes Especiais (Logística) \\
\hline Entrevistado 5 & 24 & $\mathrm{M}$ & GE Oil \& Gas & 2 & Estagiário de Serviços \\
\hline Entrevistado 6 & 45 & $\mathrm{M}$ & GE Oil \& Gas & 9 & Gerente de Projetos de Serviços (Líder da integração de supply chain GE e Baker) \\
\hline Entrevistado 7 & 39 & $\mathrm{M}$ & GE Oil \& Gas & 9 & Senior Project Staff Manager \\
\hline Entrevistado 8 & 40 & $\mathrm{M}$ & GE Oil \& Gas & 20 & Installation Manager \\
\hline Entrevistado 9 & 38 & $\mathrm{M}$ & GE Oil \& Gas & 16 & Lead Sourcing Specialist \\
\hline Entrevistado 10 & 22 & $\mathrm{M}$ & BHGE & 1,5 & Estagiário de Instalação \\
\hline
\end{tabular}

Fonte: Elaboração própria

Levando em consideração o nível organizacional dos entrevistados, temos que $20 \%$ deles estão em um nível de gerência sênior, $30 \%$ em nível de gerência, $20 \%$ em nível de analistas e $30 \%$ em nível de estagiários.

Gráfico 1: Nível Organizacional dos Entrevistados

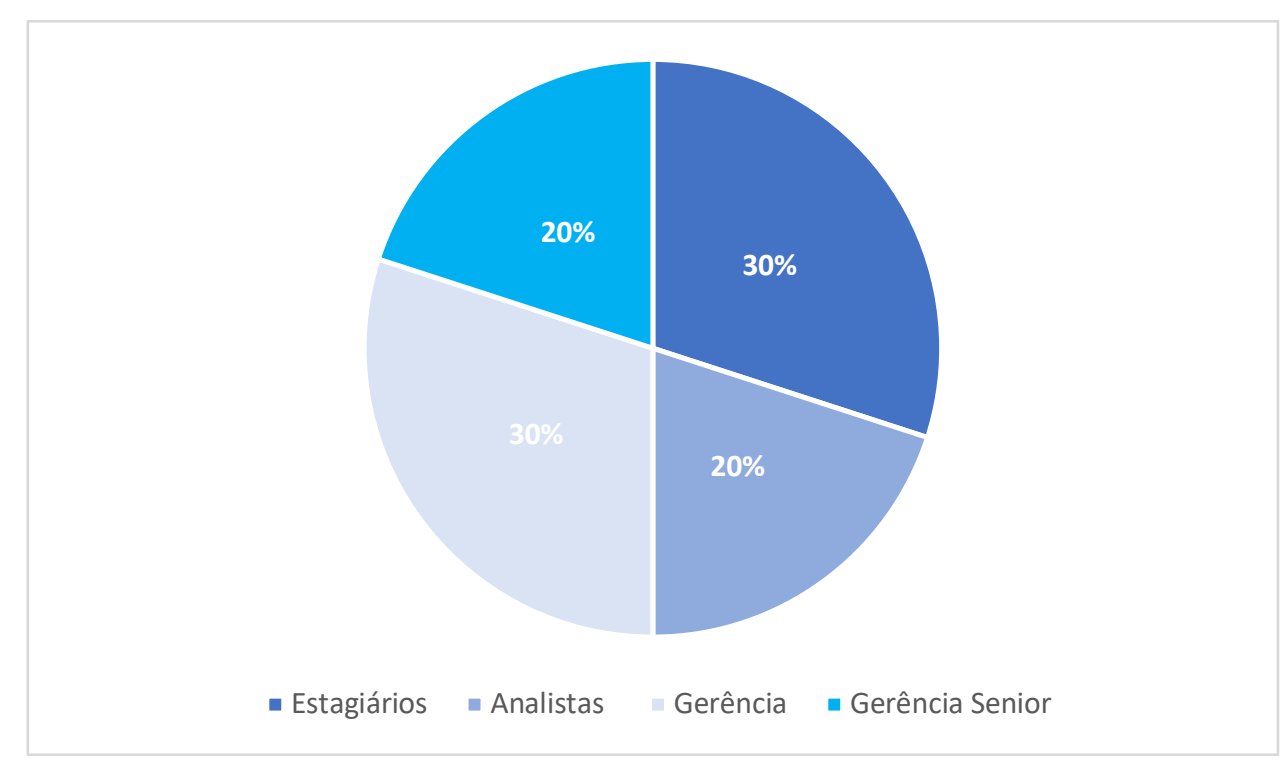

Fonte: Elaboração própria

Dentro do subconjunto de entrevistados da Baker, foram entrevistados um homem branco e uma mulher negra. O tempo médio de casa é de 5,5 anos, a idade média deles é de 27,5 anos, ambos passaram apenas pela Baker em suas trajetórias profissionais, são brasileiros e nasceram no estado do Rio de Janeiro. 
Considerando apenas os entrevistados GE Oil \& Gas, temos um grupo 5 de homens brancos e um negro, o que equivale a respectivamente 83,3 e $16,7 \%$ do total de entrevistados nessa empresa. A idade média deles é de 37,5 anos e o tempo médio de casa é de 10,5 anos, dentro do grupo foram entrevistados 2 italianos e 4 brasileiros, sendo 1 do Espírito Santo, 1 da Bahia, e 2 do Rio de Janeiro. Dentro desse grupo, 33,3\% trabalhou apenas na GE e os outros $67,7 \%$ já passaram por outras empresas.

Dentro do pool da BHGE, temos dois homens brancos como entrevistados. A idade média deles é de 22,5 anos, tem 1,5 anos de casa, ambos já trabalharam em outras empresas e nasceram no estado do Rio de Janeiro.

Tabela 2: Dados Médios dos Entrevistados

\begin{tabular}{|c|c|c|c|c|c|}
\hline Empresa & № de Entrevistados & Idade Média & Sexo & Tempo Médio de Casa & Nacionalidade \\
\hline Baker Hughes & 2 & 27,5 & Dividido igualmente em 50\% & 5,5 & Todos Brasileiros \\
\hline GE Oil \& Gas & 6 & 37,2 & $100 \%$ Homens & 10,5 & $33,3 \%$ Italianose $67,7 \%$ Brasileiros \\
\hline Baker Hughes & 2 & 22,5 & $100 \%$ Homens & 1,5 & Todos Brasileiros \\
\hline
\end{tabular}

Fonte: Elaboração própria

Se faz necessário ressaltar que o entrevistado número 6 , hoje gerente de projetos dentro do departamento de serviços na Product Line TPS, foi o responsável por organizar a integração de supply chain da GE Oil \& Gas e da Baker em 2016 em toda a América Latina.

Outro fato que precisa ser dito é que o entrevistado número 8 , com mais de 20 anos de casa, entrou na empresa através do programa de trainee da empresa dentro da Nuovo Pignone, em Bari, na Itália. Na época a empresa já pertencia ao grupo $G E$, mas a mesma ainda não havia extinguido a marca da antiga estatal italiana. Esse entrevistado acompanhou, como membro da empresa, mais de 83\% da história da GE na indústria de óleo e gás, tendo sendo testemunha de grande parte das mudanças pela qual a mesma passou, trabalhado em mais de 10 países diferentes e 5 continentes, traz grandes contribuições para a pesquisa. 


\subsection{Método de Pesquisa}

Cada entrevistado respondeu a 11 diferentes questões, elaboradas pelo autor que gerou o roteiro de pesquisa que se encontra no Anexo 1 e que o ajudaram a entender a percepção dos funcionários de diferentes níveis organizacionais e diferentes backgrounds sobre a cultura e a estrutura no qual operam há quase dois anos. Dentro do anexo 1, se poderá encontrar o roteiro de pesquisa elaborado com as perguntas feitas aos entrevistados.

As entrevistas foram feitas presencialmente com todos os entrevistados, menos o número 7, este estava no Espírito Santo no dia e para não prejudicar a programação do projeto realizou a entrevista por Skype.

Os resultados das entrevistas serão comparados aos dados disponibilizados pela empresa publicamente sobre sua estrutura e cultura e ao que os teóricos do campo escreveram sobre o assunto.

Através dessa triangulação de resultados, acredita-se ser possível analisar a cultura e a estrutura organizacional desse grande player do setor de equipamentos e serviços para óleo e gás e identificar se o que foi escolhido pela liderança da empresa está de fato sendo percebido pelos colaboradores e se o mesmo é o ideal de acordo com a teoria.

\subsection{Limitações da Pesquisa}

Dentro do modelo de pesquisa proposto, foram percebidas algumas limitações pelo autor. O planejamento inicial era realizar todas as entrevistas presencialmente, sendo possível analisar tanto a linguagem verbal como o corporal dos entrevistados. Infelizmente, como o entrevistado número 7 não estava na cidade no período de entrevistas, a mesma teve que ser feita através de uma chamada no Skype.

Dada a agenda dos membros da organização, não foi possível entrevistar pessoas de níveis organizacionais mais altos, como diretores, vice-presidentes e 
officers. Pessoas nesses níveis mais altos trariam opiniões e pontos de vista mais estratégicos e uma visão mais global do que foi feito.

Por último, dado o ciclo profissional do autor, grande parte dos entrevistados foi das Product Lines de Turbo Machinery and Process Solutions (TPS) e Oil Field Services (OFS), o que pode enviesar o estudo para alguma particularidade dessas duas áreas. 


\section{Análise}

\subsection{Introdução à Análise}

Como visto no capítulo 3, um dos maiores chamarizes usados pela GE para anunciar a aquisição da Baker foi que a nova BHGE seria a primeira empresa fullstream do mundo. Para sustentar esse modelo de negócios, a mesma estruturou a nova empresa em 4 linhas de produto diferentes: Digital, TPS, OFE e OFS e diversos órgãos de staff.

Além disso, a empresa buscava integrar seus funcionários sob uma mesma cultura organizacional. Como comentado por Chiavenato (2010) uma cultura organizacional forte tem um grande impacto nos resultados das empresas, sendo que a falta de integração desse fator é um dos maiores responsáveis pelos fracassos em M\&As de acordo com os estudos de Weber, Tarba e Oeberg (2013) e Kelly (2015).

Serão confrontadas, nos subcapítulos seguintes, à teoria apresentada no capítulo 2, as informações que a empresa apresentou no capítulo 3 e as entrevistas realizadas pelo autor e detalhadas no capítulo 4 .

Para enriquecer o estudo e facilitar a análise, serão transcritas durante o texto as falas de alguns dos entrevistados.

\subsection{Estrutura Organizacional}

No capítulo 3, foi demonstrado que a GE escolheu para a BHGE uma estrutura de linha-staff, com departamentalização por produtos. Nesse modelo, de acordo com Chiavenato (2001), tem-se órgãos de staff (no caso da BHGE, podem-se citar os recursos humanos, finanças e jurídico, entre outros) prestando assessoria aos órgãos de linha, esses que estão departamentalizados em 4 linhas de produto: TPS, OFE, OFS e Digital.

Como confirmado pelas entrevistas, a escolha pela departamentalização por produtos trouxe uma desvantagem desse modelo já citada por Chiavenato (2001): a 
falta de integração. Os membros da empresa, nos mais diferentes níveis, comentaram que mesmo hoje, 3 anos depois da aquisição ser anunciada e 2 anos depois de ser posta em prática, mesmo estando no mesmo escritório, cada linha opera individualmente como uma empresa própria.

\footnotetext{
"Entrei como BHGE, mas sempre foram muito separadas as duas empresas, exemplo tem estagiário Baker, estagiário GE, funcionário Baker e funcionário GE. Não integrou (...) até hoje em dia, mesmo sendo uma empresa só continua sendo Baker e GE” (Entrevistado 1).

"A integração foi péssima, até hoje não integrou direito. (...) se eu tiver que dar uma nota, a nota é baixa" (Entrevistado 7).

"É claro que a fusão da empresa, (...) no nível pessoal não está estruturado. Se conheço o nome de 6 ou 7 funcionários da Baker é muito pra mim" (Entrevistado 8).
}

"Me reconheço como Baker, não sei explicar" (Entrevistada 3).

\subsubsection{Sistemas e Processos}

Colaboradores das antigas empresas disseram que continuam utilizando os mesmos sistemas e processos que utilizavam antes da fusão, sendo esses diferentes uns dos outros, e que a mesma não afetou as suas tarefas diárias. Enquanto, por exemplo, a equipe de logística de OFS (antiga Baker) utiliza o SAP, a equipe de TPS (antiga GE) utiliza o Oracle, não bastando isso, a logística de OFS mantém a estrutura de sua antiga empresa, sendo distribuída ao redor de suas diferentes regiões, enquanto a de TPS fica centralizada em Florença, sede da linha de produto.

"É um item que agregou, não mesclou (falando sobre as áreas de produtos).

(...) Em termos de processos ainda está individualizado" (Entrevistado 9).

"Zero mudança (falando sobre a forma de trabalhar e os processos), é uma questão que a gente sente (...) o sistema é o mesmo da Baker, totalmente diferente do que o time de logística de Oil \& Gas (...) lá da GE usa, trabalhamos de maneiras totalmente diferentes. Esse tipo de integração de trabalho não existiu" (Entrevistada 3). 
"A nível de processos não vi muitas mudanças, ainda é muito forte a componente vertical do $P \& L$ (linha de produto) e acho que também são negócios muito diferentes, o negócio de Turbomachinery é diferente do negócio da Baker. É óleo e gás, mas tem um cycle time completamente diferente. Nesse momento não vejo muitas possibilidades de desfrutar de best practices, field service engineers, ferramentas (...) são áreas de conhecimento muito específicas" (Entrevistado 6).

"Honestamente eu não senti nenhuma diferença (falando sobre a mudança de processos)" (Entrevistado 5).

"Pelo que eu percebi são um pouco diferentes os processos, eu na verdade não sei como é a logística na GE Oil \& Gas (...) a gente usa SAP, na Baker a gente usa $S A P^{\prime \prime}$ (Entrevistado 4).

"Os processos (ainda) são os mesmos, os sistemas (ainda) são os mesmos" (Entrevistado 9).

Há diferentes suportes de RH para funcionários GE e Baker. Em 2019, há pessoas que cuidam especificamente dos funcionários que vieram de cada empresa (diferentes processos, salários e benefícios), sendo que ainda hoje todos os funcionários são contratados como GE ou como Baker e não como BHGE, embora trabalhem para a BHGE.

"Eu acho que isso é um ponto super negativo e mostra que a integração não ocorreu 100\%. A gente tem um RH Baker, um RH GE, benefícios Baker, benefícios GE (...) existe uma divisão. Nós estamos como BHGE mas existe muito essa divisão, de quem é Baker e quem é GE e isso começa pelo RH. Os recursos humanos que olham pelo empregado deveriam ser integrados" (Entrevistada 3).

Além disso, cada linha de produto tem seus próprios objetivos e seus órgãos de staff para suportá-los (BAKER HUGHES, 2017). Treinamentos, objetivos, comunicações e planos são traçados de forma vertical e não transversal, mantendo as linhas ilhadas, umas em relação as outras. Dessa forma, como comentado pelos entrevistados, há uma dificuldade grande na integração de atividades, pessoas e projetos.

Um exemplo claro é na área de vendas: existe um diretor para cada linha, com objetivos individuais para seus produtos. Como há uma estratégia de remuneração com bônus, a falta de integração desses objetivos e de conhecimento 
dos produtos e serviços ofertados por diferentes linhas, faz com que cada área se esforce para vender apenas o que oferta, impossibilitando a venda de projetos integrados fullstream. Até hoje, apenas um projeto desses foi desenvolvido: ainda em 2017, a Twinza Oil comprou com a BHGE um deles em Nova Guiné (OFFSHORE ENERGY TODAY, 2017).

"(Sobre a percepção do cliente sobre a empresa) Exite um comercial para cada área, então quando você tem um contrato de tubos, que é um produto GE, é GE. Quando você tem algo já de drilling, que é um produto da Baker, é Baker" (Entrevistada 3).

Como demonstrado por Chiavenato (2010) o modelo de departamentalização por produtos, que é observado na BHGE, traz um grande problema na integração entre as diferentes áreas. Como pode ser visto na fala da entrevistada 3, cada linha de produto tem sua própria equipe comercial, esta que dificilmente se comunica com ou possui conhecimento para ofertar produtos das outras. Com isso, cada uma foca apenas no seu portfólio, suas metas e seus objetivos, dificultando a integração e a percepção de todos serem parte de uma única empresa.

\subsection{Cultura Organizacional}

\subsubsection{Percepção e Símbolos}

Foi mencionado também por eles que, embora as quatro linhas de produto estejam localizadas dentro do mesmo escritório, percebe-se facilmente quem é "legacy GE" e quem é "legacy Baker".

"É muito comum (ouvir se referirem a alguém como legacy GE ou legacy Baker), é uma coisa que a gente sabe (quem veio de qual empresa) (...) eu sinto muito isso, esse aqui é Baker, esse aqui é GE, o jeito é muito diferente (...) existe uma divisão, um jeito diferente" (Entrevistada 3).

Uma das formas de identificação é a vestimenta, enquanto os funcionários advindos da GE usam roupas consideradas mais formais (camisas sociais, calça e sapato), aqueles que vieram da Baker se apresentam no escritório de forma mais "despojada" (camisas polo, tênis e jeans). Os uniformes são um dos símbolos citados por Robbins, Judge e Sobral (2011) para identificar a cultura organizacional, 
o fato de que os funcionários se vestem de maneira diferente pode indicar que há duas subculturas divergentes (ROBBINS, JUDGE e SOBRAL, 2011).

"Da pra ver, da pra ver (sobre se consegue identificar quem é legacy GE e legacy Baker) (...) no estilo da pessoa você vê. (...) A GE é muito a aparência, (...) pessoal bem 'arrumadinho' é GE, com certeza, não que a Baker não seja arrumada, mas a GE quer andar de roupa de marca, funcionário GE quer andar com o sapato polido" (Entrevistado 7).

"A Baker tinha (...) uma coisa mais despojada, aqui na $G E$ as pessoas vinham trabalhar até com um dress code, uma coisa muito formal, as pessoas vindo trabalhar aqui de terno (...) como o pessoal da Baker é mais uma coisa de campo, de logística de materiais, já era uma coisa mais despojada" (Entrevistado 2).

"(Falando sobre a vestimenta) O pessoal da Baker é mais operacional, então ao invés de ser como a gente que sai pra encontrar o cliente eles as vezes podem até encontrar o cliente, mas no campo. É uma cultura um pouquinho diferente. (...) Acho que vai ser integrado sim, porque a empresa tem que criar um certo dress code" (Entrevistado 6).

"Eu percebo uma diferença (se referindo a vestimenta)" (Entrevistado 8).

"Tem uma diferença sim, o pessoal da Baker, não pra dizer mais informal mas sabe? O pessoal da GE é mais 'engomadinho'. Eu não acredito que o pessoal da Baker tenha mudado a forma de (vir) trabalhar, mas acredito que tenha sido um impacto grande" (Entrevistado 4).

“A vestimenta, estagiário GE vem 'super arrumado', estagiário Baker é polo, camisa normal" (Entrevistado 1)

Outro fator que pode gerar uma falta de integração cultural tem a ver com um símbolo simples: o crachá. Embora a GE tenha exigido que os funcionários da Baker emitissem novos crachás BHGE, os que vieram da GE Oil \& Gas não o tiveram que fazer e, como comentado pelos entrevistados, se mantém até hoje com os crachás GE.

"Teve que trocar, todo mundo (da Baker) recebeu um (crachá) novo depois (...) era uma mudança natural" (Entrevistado 4).

"Eu acho que os funcionários ficaram com o crachá GE por um simples desleixo e não exigência da própria GE (...) para gente não foi falado que tinha que mudar" (Entrevistado 9). 
Além disso, como discutido nas entrevistas, é comum ver camisas, casacos e capacetes de obra com as logomarcas das antigas empresas presentes no escritório.

"É normal, casaco da Baker pendurado na cadeira, pessoal de polo com a marca da empresa antiga, até chapéu de obra de GE a gente acha jogado por ai" (Entrevistado 10).

Os colaboradores que vieram da Baker comentaram, inclusive, que embora tenham recebido emails @bhge, os emails @bakerhughes continuam funcionando e que eles continuam utilizando os mesmos por se identificarem mais com a marca.

"Não, continuo usando o email Baker, tem os dois, mas a gente usa o Baker" (Entrevistada 3).

Um último símbolo que vale ser notado tem a ver com as "matrículas" dos funcionários. Enquanto na GE é utilizado o Single Sign On (SSO), a Baker tinha o seu 4-3-1 para registrar os funcionário. Com a únião todos os funcionários da Baker receberam um SSO, porém, ainda hoje utilizam a matrícula antiga para entrar em seus computadores e sistemas. Esse é mais um dos símbolos que mantém separadas as duas empresas.

"Até pra mandar email, o pessoal da GE fala 'pega ai o meu SSO', na Baker é 4-3-1 (...) é diferente. (...) Eles me deram SSO, mas eu também tenho 4-31, continua funcionando assim como meu email Baker" (Entrevistada 3).

"Tem 4-3-1 ainda (...) assim que aconteceu a fusão todo mundo recebeu SSO automaticamente (...) (sobre se continuam usando o 4-3-1) sim, é 4-31, pra logar no computador é 4-3-1, pra usar o SSO é mais pra entrar em alguns sites da GE que pedem, mas SAP, computador é tudo 4-3-1" (Entrevistado 4).

Essa falta de unificação dos símbolos apresentados pelos grupos, é mais um indício da presença de diferentes subculturas na empresa (ROBBINS, JUDGE e SOBRAL, 2011).

\subsubsection{Espaço Físico}


Robbins, Judge e Sobral (2011) acreditam que o espaço físico é um ponto importante da cultura organizacional. Para facilitar operacionalização todos foram alocados nos mesmos escritórios e as pessoas de uma mesma linha de produto são alocadas em baias próximas umas das outras, fazendo com que as únicas que tem contato direto com pessoas de linhas diferentes sejam aquelas que estão nas "periferias" de cada linha.

Isso faz com que antigos grupos se mantenham e novos sejam ainda mais difíceis de formar, um dos entrevistados acredita que esse seja uma grande barreira a integração:

\footnotetext{
"Quando começar a misturar o operacional em um quadrado desses (baia) que a gente tem aqui, que tem geralmente só gente de GE ou só gente da Baker (...) ai (a integração) vai mais fácil" (Entrevistado 9).
}

\subsubsection{Rituais}

Uma das mais importante formas de perpetuar a cultura organizacional, segundo Robbins, Judge e Sobral (2011), são os rituais. Esses, que vão desde simples reuniões até festas e eventos das empresas são muito utilizados para passar a cultura para os novos colaboradores.

Um evento que é tradicionalmente desenvolvido para gerar integração e empresa é a festa de fim de ano. Na BHGE, porém, cada linha de produto tem sua festa separada, o que na opinião dos entrevistados dificulta que eles conheçam pessoas de outras áreas de atuação.

"Não só a festa de fim de ano, mas a gente teve várias comemorações e é sempre só TPS. No fim do ano passado eu até lembro que foi todo mundo comemorar o fim de Q4 no 348, mas cada linha de produto reservou o restaurante em uma hora diferente, não teve integração" (Entrevistado 10).

A GE oferece, por outro lado, em todos as suas empresas diferentes atividades e eventos. Há diversos "hubs" que organizam atividades esportivas (futebol e corridas, por exemplo), ações de voluntariado, palestras e round-tables com figuras de liderança, que tem como objetivo integrar seus colaboradores sob a 
mesma marca. Foi comentado, porém, por diversos entrevistados, que os funcionários da Baker não costumam frequentar esses eventos.

"Não só a festa de fim de ano, mas a gente teve várias comemorações e é sempre só TPS. No fim do ano passado eu até lembro que foi todo mundo comemorar o fim de Q4 no 348, mas cada linha de produto reservou o restaurante em uma hora diferente, não teve integração" (Entrevistado 10).

"A gente tem vários treinamentos o HUB do EID, que é o grupo de estagiários e os estagiários da Baker não se viam (como pertencentes ao grupo), achavam que não podiam entrar, não tavam presentes e tavam perdendo muito do que o estágio pode oferecer" (Entrevistado 1).

"(Quando questionada do por que de ter pessoas da Baker que não vão aos eventos) Tem gente que é assim (...) a GE tem as ferramentas, mas a pessoa tem que buscar, óbvio que cada um é de um jeito, as vezes você não se sente a vontade, sente um pouco essa exclusão" (Entrevistada 3)

"Eu tentava ir sempre que eu pude, mas entrou um pessoal novo e eu não sei se eles tem esse costume (de ir aos eventos da GE)" (Entrevistado 4). 


\section{Conclusão}

O objetivo desse estudo foi entender a estrutura organizacional escolhida para a BHGE e a integração cultural pela qual a empresa passou com o processo de fusão, além de avaliar se os mesmos foram bem sucedidos.

Ao analisar o caso da integração estrutural e cultural de uma das maiores empresas de um mercado centibilhonário e que é parte de um conglomerado que há mais de 120 anos está na vanguarda das técnicas de gestão mundiais, espera-se apresentar resultados que possam contribuir para o campo de conhecimento acadêmico do estudo de organizações.

Para alcançar esses objetivos, através de um roteiro de pesquisa de 11 perguntas desenvolvido pelo autor, foram realizadas entrevistas qualitativas com 10 membros dessa organização. Esse roteiro focou no entendimento da percepção dos funcionários sobre o processo de fusão pelo qual a empresa passou e através das respostas fornecidas, foi possível analisar a integração e a cultura da empresa com base na teoria apresentada no capítulo 2.

Como demonstrado no capítulo 4, as pessoas escolhidas para essas entrevistas pertencem a diferentes níveis organizacionais e se tornaram BHGE através de diferentes caminhos. Contribuiram para esse estudo, pessoas que vieram da Baker Hughes, da GE Oil \& Gas e algumas que foram contratadas já como BHGE; desde estagiários até gerentes continentais senior e pessoas de 1,5 a 20 anos de casa. Além disso, dada a diversidade da empresa, foi possível entrevistar não apenas funcionários brasileiros, mas também extrangeiros.

Com relação aos resultados da pesquisa, de acordo com os modelos propostos por Chiavenato (2010), a estrutura organizacional escolhida pela empresa foi a de linha-staff com uma departamentalização por produtos (BAKER HUGHES, A GE COMPANY, 2017). Através das entrevistas, pôde-se notar que estruturando-a em 4 linhas de produtos independentes (TPS, OFE, OFS e Digital), a GE dificultou o processo de integração, criou linhas com objetivos, processos e sistemas diferentes, além de impedir que uma das principais vantagens competitivas que a mesma teria (a realização de projetos fullstream) se realizasse de fato. 
Ficou claro na fala dos entrevistados que eles têm pouco ou nenhum contato com aqueles de outras linhas de produto, mesmo estando localizados no mesmo espaço físico. A falta de compartilhamento de sistemas, objetivos e processos dificulta a integração dos funcionários e das áreas em sim, prejudicando a empresa e as sinergias que poderiam surgir dessa união, um exemplo claro dessas é a realização de projetos fullstream, uma grande oportunidade de vantagem competitiva, mas que a empresa não aproveita de fato.

Ao nível de cultura organizacional, embora a $G E$ tenha tomado algumas decisões com o objetivo de facilitar a integração, percebe-se pelos comentários dos colaboradores que o mesmo não ocorreu. Com objetivos, planos, benefícios e símbolos diferentes, os funcionários não se veem, 3 anos após o anúncio da fusão como uma empresa, mas sim como funcionários GE ou funcionários Baker.

Esse fato pode ser explicado por diferentes exemplos citados nas entrevistas transcritas no capítulo 5. Um dos sinais mais fortes, como demonstrado, é que mesmos os funcionários que foram contratados após a fusão, passaram por processos diferentes, tem benefícios diferentes e trabalham apenas com as pessoas de sua área. Essas irão compartilhar apenas os valores, histórias e a própria cultura com a qual se identificam, então mesmo sendo contratados como BHGE, os novos colaboradores passam por um processo que os torna Baker Hughes ou GE Oil \& Gas.

Outro fator que influencia a cultura é a coleção de símbolos das antigas empresas que hoje ainda é visto no escritório. Como os colaboradores não se identificam com a marca BHGE e sim com suas "progenitoras", é comum notar funcionários com casacos e camisas polo das empresas antigas, reforçando a ideia de que há duas empresas sob o mesmo teto.

Mais um símbolo da cultura que mostra a clara divisão das duas empresas é a vestimenta. Funcionários advindos de ambas as empresas comentaram que conseguem identificar facilmente quem veio da empresa oposta através das roupas que usam no dia-a-dia, sendo que os funcionários da Baker descreveram os da GE como "engomadinhos" e os da Baker foram descritos pelos GE como "despojados".

Por último, pelo fato que os funcionários de uma empresa, não só conseguem identificar os da outra facilmente e usam os termos "legacy GE ou legacy Baker" 
para se referir a eles, mas ainda se percebem como funcionários $G E$ ou Baker, e não BHGE, nota-se claramente uma divisão interna.

Com isso, vemos que o processo de integração realizado na BHGE não foi bem-sucedido. Da forma que foi feito, existem sob a marca da BHGE duas empresas distintas operando. A GE Oil \& Gas, com seus funcionários identificados com a marca, crachás GE, roupas formais e indo aos eventos que a holding proporciona, e os funcionários da Baker, ilhados na linha de OFS, ainda usando seus 4-3-1, não se sentido parte da nova empresa e por isso evitando ir em eventos de integração.

Acredita-se ser importante ressaltar que a percepção dos funcionários foi muito semelhante nos tópicos abordados. Os entrevistados, de todos os backgrounds e com os mais variados tempos de casa e níveis organizacionais, fizeram comentários que se reforçam, indicando que o que está ocorrendo é de percepção comum na organização.

Embora tenha-se analisado o caso da integração estrutural e cultural de uma das maiores empresas de um mercado centibilhonario e que é parte de um conglomerado que há mais de 120 anos está na vanguarda das técnicas de gestão mundiais, não foi possível perceber boas práticas a serem replicadas pelo mercado pois a percepção do autor é que essa integração não foi bem feita pela empresa e resultou em duas culturas diferentes operando sob a mesma marca.

Como colocado por Weber, Tarba e Oeberg (2013) e Kelly (2015), as integrações estrutural e cultural são dois dos fatores mais relevantes para o fracasso em M\&As. Com base na teoria e no que foi analisado na empresa, embora fora do escopo desse estudo, o autor percebe como acertada a posição da GE em vender sua participação na BHGE (GRYTA, 2019) tornando a empresa independente novamente. A GE não conseguiu integrar corretamente as duas empresas e, até que isso seja feito, a mesma não conseguirá encontrar os resultados esperados, ao tornar a empresa independente, essa terá mais liberdade para se reestruturar e escolher sua própria cultura.

Como o objetivo desse estudo não era analisar a venda da BHGE pela $G E$, não foram trazidas a frente novas informações sobre o assunto. Porém, o autor acredita que um estudo acerca desse novo movimento seja de grande relevância 
para o cenário acadêmico e de mercado, para que possa-se entender como a nova empresa irá corrigir os erros do passado e se integrar como uma só.

É importante notar que, dado o ciclo profissional do autor, grande parte dos entrevistados foi das Product Lines de TPS e OFS, o que pode enviesar o estudo para alguma particularidade dessas duas áreas.

Por último, como colocado no capítulo 4, uma limitação clara desse estudo é que não foi possível entrevistar membros da organização de níveis de direção, vicepresidentes e officers. Com isso, não se pode entender a percepção da liderança sobre o processo que ocorreu, como as decisões estratégicas foram tomadas e como a empresa seguirá para o futuro. 


\section{Referências Bibliográficas}

AQUES, E. The Changing Culture of a Factory. Londres: Tavistock, 1951.

BAKER HUGHES. Annual Report 2012. Baker Hughes. Houston. 2012.

BAKER HUGHES. 2016 Annual Report. Baker Hughes. Housten. 2016.

BAKER HUGHES. GE Oil \& Gas and Baker Hughes Integration Planning Update for Employees. $\quad$ SEC, $2017 . \quad$ Disponivel em: $<$ https://www.sec.gov/Archives/edgar/data/808362/000095010317003876/dp75486_ 425-ipu.htm>. Acesso em: 22 Setembro 2019.

BAKER HUGHES, A GE COMPANY. Baker Hughes and GE Oil \& Gas Complete Combination. Baker Hughes, a GE Company, 2017. Disponivel em: $<$ https://www.bhge.com/news/baker-hughes-and-ge-oil-gas-complete-combinationpress-release>. Acesso em: 8 Setembro 2019.

BAKER HUGHES, A GE COMPANY. BHGE Infographic. BHGE Infographic, 2017. Disponivel em: <https://www.bhge.com/sites/default/files/2017-07/BHGE101Infographic.pdf>. Acesso em: 8 Novembro 2019.

BAKER HUGHES, A GE COMPANY. 2018 Annual Report. Baker Hughes, a GE Company. Houston. 2018.

BAKER HUGHES, A GE COMPANY. BAKER HUGHES, A GE COMPANY ANNOUNCES CLOSING OF SECONDARY OFFERING BY GE AND ITS SHARE REPURCHASE. Baker Hughes, a GE Company. Houston. 2019.

BLOOMBERG. Charting GE's Historic Rise and Tortured Downfall. Bloomberg, 2019. Disponivel em: <https://www.bloomberg.com/graphics/2019-general-electricrise-and-downfall/>. Acesso em: 22 Setembro 2019.

BLOOMBERG. Oilfield Service Market to Value at US\$330 Bn at 3.7\% CAGR by 2026 | | Exclusive Report by Fortune Business Insights. Bloomberg, 2019. Disponivel em: <https://www.bloomberg.com/press-releases/2019-05-07/oilfieldservice-market-to-value-at-us-330-bn-at-3-7-cagr-by-2026-exclusive-report-byfortune-business-insights>. Acesso em: 8 Novembro 2019.

CHIAVENATO, I. Teoria Geral da Administração. Rio de Janeiro: Campus, 2001. 
CHIAVENATO, I. Gestão de Pessoas: o novo papel dos Recursos Humanos nas organizações. Rio de Janeiro: Elsevier, 2010.

COLVIN, G. The Ultimate Manager In a time of hidebound, formulaic thinking, General Electric's Jack Welch gave power to the worker and the shareholder. He built one hell of a company in the process. Fortune Magazine, 1999. Disponivel em: <https://archive.fortune.com/magazines/fortune/fortune_archive/1999/11/22/269126/i ndex.htm>. Acesso em: 22 Setembro 2019.

COMPANIES HISTORY. Baker Hughes, Inc. history, profile and corporate video. Companies History, $2019 . \quad$ Disponivel em: <https://www.companieshistory.com/baker-hughes/>. Acesso em: 22 Setembro 2019.

GENERAL ELECTRIC. GE AND BAKER HUGHES AGREE TO CREATE NEW FULLSTREAM DIGITAL INDUSTRIAL SERVICES COMPANY. General Electric. Boston. 2016.

GENERAL ELECTRIC. GE Oil \& Gas Overview Supplemental Transaction Information Selected Financial Information. General Electric. Londres. 2017.

GENERAL ELECTRIC. Thomas Edison \& The History of Electricity. General Electric. Disponivel em: <https://www.ge.com/about-us/history/thomas-edison>. Acesso em: 22 Setembro 2019.

GERHARDT, T.; SILVEIRA, D. Métodos de Pesquisa. Porto Alegre: UFRGS, v. 1, 2019.

GRYTA, T. GE to Give Up Majority Control of Baker Hughes. The Wall Street Journal, 2019. Disponivel em: <https://www.wsj.com/articles/ge-to-give-up-majoritycontrol-of-baker-hughes-11568154610>. Acesso em: 22 Setembro 2019.

GRYTA, T. GE to Revisit Financial-Services Unit After Fixing Power Division. The Wall Street Journal, 2019. Disponivel em: <https://www.wsj.com/articles/ge-torevisit-financial-services-unit-after-fixing-power-division-11558555799>. Acesso em: 22 Setembro 2019.

HALLIBURTON. HALLIBURTON AND BAKER HUGHES REACH AGREEMENT TO COMBINE IN STOCK AND CASH TRANSACTION VALUED AT \$34.6 BILLION. Halliburton. Houston. 2014. 
HALLIBURTON. Halliburton and Baker Hughes Announce Termination of Merger Agreement. Halliburton. Houston. 2016.

HAMPTON, L.; SCHEYDER, E. GE closes Baker Hughes deal, becomes No. 2 oilfield service provider. Reuters, 2017. Disponivel em: <https://www.reuters.com/article/us-baker-hughes-m-a-ge/ge-closes-baker-hughesdeal-becomes-no-2-oilfield-service-provider-idUSKBN1901RJ>. Acesso em: 8 Setembro 2019.

HARTUNG, A. GE Needs A New Strategy And A New CEO. Forbes, 2017. Disponivel em: <https://www.forbes.com/sites/adamhartung/2017/03/28/ge-needs-anew-strategy-and-a-new-ceo/\#2fae50ec4ad2>. Acesso em: 22 Setembro 2019.

INPHANTRY. BRANDING: WHY IT MATTERS MORE THAN YOU THINK. Inphantry, 2012. Disponivel em: <https://www.inphantry.com/branding-why-itmatters-more-than-you-think/>. Acesso em: 22 Setembro 2019.

KELLY, M. Co-Evolutionary Integration: A Complexity Perspective on Mergers \& Acquisitions. Emergence: Complexity \& Organization, Phoenix, Julho 2005.

MACRO TRENDS. WTI Crude Oil Prices - 10 Year Daily Chart. Macro Trends, 2019. Disponivel em: <https://www.macrotrends.net/2516/wti-crude-oil-prices-10year-daily-chart>. Acesso em: 22 Setembro 2019.

MALIK, M. et al. Mergers and Acquisitions: A Conceptual Review. International Journal of Accounting and Financial Reporting , Skudia, v. 4, n. 2, p. 520-533, Novembro 2014.

MARKETS \& MARKETS. Oilfield Services Market worth $\$ 125.5$ billion by 2022. $\begin{array}{lllll}\text { Markets } & \& & \text { Markets, } & 2019 . & \text { Disponivel }\end{array}$ <https://www.marketsandmarkets.com/PressReleases/oilfield-services.asp>. Acesso em: 8 Novembro 2019.

MINTZBERG, H. Criando Organizações Eficases - Estruturas em 5 Configurações. São Paulo: Atlas, 1995.

MURRAY, M. Why Jack Welch's Leadership Matters to Businesses World-Wide. The Wall Street Journal, $2001 . \quad$ Disponivel em: 
<https://www.wsj.com/articles/SB999643263420646756>. Acesso em: 22 Setembro 2019.

OFFSHORE ENERGY TODAY. Baker Hughes scores its first fullstream deal with Gulf of Papua project award. Offshore Energy Today, 2017. Disponivel em: $<$ https://www.offshoreenergytoday.com/baker-hughes-scores-its-first-fullstream-dealwith-gulf-of-papua-project/>. Acesso em: 12 Outubro 2019.

OLIVEIRA, D. D. P. R. Sistemas, Organizações e Métodos: Uma Abordagem Gerencial. São Paulo: Atlas, 1994.

OWLER. BHGE's Competitors, Revenue, Number of Employees, Funding and Acquisitions. Owler, 2019. Disponivel em: <https://www.owler.com/company/bhge>. Acesso em: 8 Novembro 2019.

OWLES, E. G.E.'s History of Innovation. The New York Times, 2017. Disponivel em: <https://www.nytimes.com/2017/06/12/business/general-electric-history-ofinnovation.html>. Acesso em: 22 Setembro 2019.

PORTER, M. Competitive Advantage. $1^{\text {a }}$ Edição. ed. Nova lorque: The Free Press, v. I, 1985.

ROBBINS, S.; JUDGE, T.; SOBRAL, F. Comportamento Organizacional. São Paulo: Pearson, v. 14, 2011.

SOBRAL, F.; PECl, A. Administração: Teoria e Prática no Contexto Brasiliero. São Paulo: Pearson Prentice Hall, 2008.

STATISTICA. Value of mergers and acquisitions (M\&A) worldwide from 1985 to 2018 (in billion U.S. dollars). Statistica, 2019. Disponivel em: <https://www.statista.com/statistics/267369/volume-of-mergers-and-acquisitionsworldwide/>. Acesso em: 15 Setembro 2019.

TREFIS TEAM. Weak US Drilling Activity To Weigh Heavily On Baker Hughes' 3Q Earnings. Forbes, $2015 . \quad$ Disponivel em: $<$ https://www.forbes.com/sites/greatspeculations/2015/10/19/weak-us-drilling-activityto-weigh-heavily-on-baker-hughes-3q-earnings/\#5b9915486081>. Acesso em: 22 Setembro 2019. 
U.S. DEPARTMENT OF JUSTICE. Justice Department Sues to Block Halliburton's Acquisition of Baker Hughes. U.S. Department of Justice, 2016. Disponivel em: <https://www.justice.gov/opa/pr/justice-department-sues-block-halliburton-sacquisition-baker-hughes>. Acesso em: 22 Setembro 2019.

WEBER, Y.; TARBA, S.; OEBERG, C. A Comprehensive Guide to Mergers and Acquisitions. New Jersey: FT Press, v. 1, 2013.

WILBERT, A.; CRUZ, H. Cultura e Clima Organizacional: uma Análise na Empresa Novo Trigo de Balneário Camboriú/sc. Simpósio de Excelencia em Gestão e Tecnologia. Resende: AEBD. 2014.

YAHOO FINANCE. General Electric Company (GE). Yahoo Finance, 2019. Disponivel em: <https://finance.yahoo.com/quote/GE?p=GE>. Acesso em: 22 Setembro 2019. 


\section{Anexo 1}

Roteiro de Pesquisa

Nome do Entrevistado:

Idade:

Sexo:

De qual empresa veio (Baker Hughes ou GE Oil \& Gas):

Tempo de casa:

Posição:

Anteriormente a fusão, qual a sua percepção quanto a própria empresa e quanto a outra (conhecia? O que achava? O que sabia sobre?)?

Quando e como soube da fusão?

O que achou da fusão?

Notou alguma mudança (nos processos, forma de trabalhar e de pensar) pós fusão?

Notou alguma mudança na forma de agir, valores da organização, crenças e hábito, forma de se vestir no ambiente de trabalho?

Já ouviu ou ouve com frequência se referirem a alguém como "pessoal da Baker ou pessoal da GE"? 
Consegue identificar com facilidade alguém que seja "legacy GE ou legacy Baker"?

Sente que está mais fácil/difícil completar suas tarefas?

Se lidera pessoas pensa que tem pouco/muito/quantidade ideal de pessoas sendo lideradas por você?

O que está melhor? E pior?

Pensa que a empresa está pronta para lidar com as mudanças no mercado? 